\title{
LOS ALCANCES DEL INCUMPLIMIENTO DE LOS DEBERES DE SEGURIDAD EN LOS EVENTOS MASIVOS: UNA MIRADA DESDE EL DERECHO DE CONSUMO
}

\section{THE SCOPE OF SAFETY DUTIES' BREACH IN MASS EVENTS: A VIEW FROM CONSUMER LAW}

Felipe Oyarzún Vargas*

\section{Resumen}

El presente artículo tiene como objetivo indagar los alcances del incumplimiento de los deberes de seguridad en el consumo por parte de un organizador de eventos masivos. Considerando que el fenómeno de la masificación en los espectáculos cada vez tiene una mayor ocurrencia en Chile y es fuente de riesgos para los asistentes, esta investigación analiza los eventos masivos desde el derecho de consumo. Siendo un tema omitido por la doctrina nacional, el presente trabajo, una vez asentada la relación existente entre este tipo de eventos y la ley de protección a los consumidores, enfatizando en los sujetos que intervienen (tanto consumidor jurídico/ material como proveedor efectivo/intermediario) y el contrato en el cual se funda esta relación, se centra en las particularidades que reviste la seguridad en los espectáculos públicos. Los alcances del incumplimiento del deber de seguridad adquieren relevancia al abordar los distintos tipos de respon-

*Abogado. Licenciado en Ciencias Jurídicas y Sociales, Universidad Alberto Hurtado. Máster en responsabilidad civil e investigador predoctoral FPI, Universidad Carlos III de Madrid. Profesor e investigador del departamento de derecho privado de la Universidad Carlos III de Madrid. Dirección postal: Calle Madrid 126, CP 28903, Getafe, Madrid, España. Correo electrónico: oyarzun@der-pr.uc3m.es

Este trabajo ha sido elaborado en el seno del Proyecto "Las fronteras del Derecho del enriquecimiento injustificado" (DER 2017-85594-C2-1-P; IP Pedro del Olmo), financiado por la Agencia Estatal de Investigación dependiente del Ministerio de Economía, Industria y Competitividad (Gobierno de España). Agradezco las observaciones efectuadas por los pares evaluadores, las cuales sin duda han ayudado a mejorar la versión final de esta investigación.

Recepción: 2021-03-11; aceptación: 2021-06-07. 
sabilidades en las cuales puede incurrir según el tipo de proveedor. Por último, se exponen los medios de exoneración que el proveedor dispone.

Palabras Clave: eventos masivos; ley del consumidor; deber de seguridad; responsabilidad civil; responsabilidad contractual

\section{AbStRact}

This paper aims to delve into the scope of safety duties' breach by mass events organizers. Considering that massive shows' trend is becoming more common in Chile and they represent a source of potential risk for attendees, this research analyzes mass events from a consumer law perspective. While being a topic omitted by Chilean doctrine, this paper focuses on the relationship between mass events and the consumer protection law, pointing out the specifications related to mass events' safety duties. Furthermore, this article put the emphasis on the actors involved (legal and material consumer as well as the intermediary and real supplier) and the contract which confirms this relationship. The breach of safety duties' scope gains importance when analyzing the diverse liabilities depending on the type of supplier. Finally, the means of exoneration for suppliers are exposed.

KEYWORDS: mass events; consumer law; duty of safety; civil liability; liability for breach of contract

\section{INTRODUCCIÓN}

El presente artículo tiene como objetivo investigar los alcances del incumplimiento de los deberes de seguridad en el consumo por parte de un organizador de eventos masivos, de forma que se proporcione una protección adecuada al asistente de un espectáculo de alta convocatoria. Comprendiendo la relación entre asistente y organizador como la de un consumidor con un proveedor, este trabajo presenta la siguiente estructura.

En la primera parte, la investigación expone algunas cuestiones preliminares. Por una parte, el incremento de espectáculos públicos en Chile, resaltando que aquellos que aglutinan a un gran número de personas en un espacio determinado configuran una fuente de potenciales riesgos a los asistentes a dicho tipo de actividades. Ello, se constata a partir de datos proporcionados por el Consejo Nacional de la Cultura y las Artes y el Servicio Nacional del Consumidor, transformando éste en un tema actual y de interés. Por otra parte, se proporciona la definición que el ordenamiento 
jurídico nacional provee de espectáculo público, destacando la ausencia de una ley propiamente tal, dejando tal labor a disposiciones de menor rango jurídico. Y, luego, producto de la proliferación de situaciones que subyacen de un evento masivo, se detalla el objeto de estudio de este trabajo.

En la segunda parte, se indaga sobre la relación entre los eventos masivos y la ley n. ${ }^{\circ} 19496$. En ese sentido, aunque se constata la falta de regulación propia sobre la materia, se explica que la LPC proporciona herramientas útiles para aproximarse a las particularidades que revisten los eventos masivos, teniendo al Código Civil como norma supletoria. Asumido ello, el trabajo aborda ciertas cuestiones puntuales de estas actividades en sede de consumo. Así, posterior a enunciar los derechos y deberes generales en estos casos, la investigación se aproxima a las nociones de consumidor (material y jurídico) y proveedor (efectivo e intermediario), enfatizando en la relación tripartita entre asistente, ticketera y productora de evento. Junto con ello, una vez definido y caracterizado el contrato de eventos masivos, se exponen los problemas que significa adoptar exclusivamente un enfoque contractual, para lo cual se plantea uno desde una óptica extracontractual.

En la tercera parte, bajo la idea de que, en principio, los espectadores no asumen riesgos al asistir a un espectáculo masivo (en razón que tienen la confianza de que el organizador habrá adoptado las medidas de resguardo necesarias), el trabajo se centrará en el derecho y el correlativo deber que surgen de la seguridad en el consumo y su relación con los espectáculos de alta convocatoria. A mayor abundamiento, se proporcionan ciertas pautas sobre los alcances de la protección en la realización de estos eventos. En este aspecto, luego de mencionar sus fuentes en la LPC y constatar las pocas sentencias en esta sede en lo relativo a la vulneración de la seguridad en espectáculos públicos, se acude a lo indicado por la jurisprudencia sobre este deber en otras situaciones de hecho y a lo expuesto por la doctrina en otros países que sí han reflexionado sobre esta materia (en cualquier caso, el trabajo dista de ser un estudio de derecho comparado).

En la cuarta parte, luego de indagar en los alcances del deber de seguridad, la investigación se complementa con el estudio de las responsabilidades que se generan a partir de su incumplimiento. En relación con ello se distingue entre el régimen de responsabilidad civil e infraccional, según se esté en presencia de un proveedor efectivo o intermediario. En concreto, el trabajo propone y fundamenta la idea de aplicar, para los casos de eventos masivos, un régimen de responsabilidad civil en el cual se beneficia a la víctima/consumidor a través de herramientas como la culpa infraccional y la aplicación de presunciones de culpa (en el caso de proveedor efectivo) y de responsabilidad objetiva (en el caso de proveedor intermediario) en las relaciones de consumo.

Por último, se desarrollan la participación del consumidor en su propio daño y la procedencia del caso fortuito como posibles medios de exoneración. 


\section{CONSIDERACIONES PREVIAS}

\section{Los eventos masivos: su comprensión como fuente de riesgos y su vigencia en Chile}

En el año 1985 más de 60000 espectadores en el estadio y el mundo a través de la señal de televisión presenciaban en vivo una de las mayores tragedias en los espectáculos masivos. Se le llamó la "Tragedia de Heysel" a la muerte de 39 espectadores y a las lesiones que sufrieron más de 600 personas previo a disputarse la final de la Copa de Europa entre Liverpool y Juventus en Bruselas, Bélgica. Independiente del resultado de los diversos juicios que se suscitaron a partir del siniestro ${ }^{1}$, el caso aludido resulta ser un adecuado botón de muestra respecto a los peligros que se pueden materializar a través de la aglomeración de personas, es decir, por la realización de eventos masivos. Este fenómeno constituye una más que potencial fuente de daños y amenazas para la seguridad de los asistentes ${ }^{2}$.

Chile no está exento de esta realidad. Año tras año, tanto en Santiago como en regiones, el número de eventos masivos en torno a la música, deportes y cultura crece más y más. Durante los últimos 20 años, se ha visto más artistas presentarse en Chile que en cualquier otro momento de la historia. Según la segunda encuesta nacional de participación y consumo cultural, que buscó medir y caracterizar el consumo cultural en Chile, diferenciando comportamientos por regiones, niveles socioeconómicos, sexo y edad, el porcentaje de la población que declaró nunca haber asistido a un concierto disminuyó de un 19,1\% en el 2005 a un 6,6\% el $2009^{3}$. Del mismo modo, la encuesta de participación cultural de 2017, elaborada por el Consejo Nacional de la Cultura y las Artes, indicó que el 30\% de la población consultada ha asistido en los últimos doce meses a un concierto de música ${ }^{4}$. Este dato debe ser relacionado con el proporcionado por el mismo organismo, quienes a través de su estudio "Política Nacional del Campo de la Música 2017-2022", indicaron que el número de recitales y conciertos aumentó en un $27 \%$ entre 2009 y 2014, extendiendo la cantidad de espectadores en un $31,2 \%$ en ese período 5 .

\footnotetext{
${ }^{1}$ La responsabilidad no fue exclusivamente de los hooligans del Liverpool, sino también de la UEFA y de los responsables de mantener la seguridad. Noticia en prensa, disponible en: https://elpais.com/diario/1991/10/18/deportes/687740406_850215.html [Fecha de consulta: 08 de marzo de 2021].

${ }^{2}$ Palazón (2002), p. 51.

${ }^{3}$ Consejo Nacional de la Cultura y las Artes (2011), p. 46.

${ }^{4}$ Consejo Nacional de la Cultura y las Artes (2017), p. 103.

${ }^{5}$ Consejo Nacional de la Cultura y las Artes (2016), pp. 28-29. Disponible en: https://www.cultura.gob.cl/wp-content/uploads/2016/11/politica_musica.pdf [Fecha de consulta: 08 de marzo de 2021].
} 
La mayor realización de espectáculos públicos ha incidido en que también los reclamos sobre los mismos se multipliquen. En ese aspecto, el SERNAC, quien ha levantado información al respecto, ha señalado que en un 73\% aumentaron los reclamos en el mercado de la entretención en 2019, pasando de 3301 quejas en 2018 a 5733 en 2019. El mismo Servicio ha puntualizado que el $56,8 \%$ de los reclamos se concentra en "producción de eventos" como conciertos o espectáculos masivos ${ }^{6}$.

De los datos expuestos, resultan dos cuestiones indubitables: en primer lugar, la peligrosidad y los riesgos que comporta la realización de esta clase de eventos; y, en segundo lugar, se constata su presencia y frecuente realización en Chile. Por ello, resulta trascendente investigar los pormenores de este fenómeno.

\section{2. ¿Qué es un evento masivo según la legislación chilena?}

Los eventos masivos o espectáculos públicos no son un tema que se caracterice por su desarrollo en Chile. A pesar de esto, es posible construir un marco sobre qué es lo que va a entenderse por evento masivo en nuestro país, a partir de lo que señala el reglamento de condiciones sanitarias, ambientales y de seguridad Básica en locales de uso público, decreto n. ${ }^{\circ} 10$ del año 2010 del Ministerio de Salud, publicado en el Diario Oficial en 25 de septiembre del año 2010. Dicho reglamento define dos conceptos que tienen particular relevancia para este trabajo. Primero, en su artículo $1 .^{\circ}$ inciso $3 .^{\circ}$, define a los locales de uso público como aquellos

"recintos o establecimientos cerrados en su perímetro y de carácter permanente, sean de propiedad pública o privada, a los que concurra público en general con fines de obtener servicios destinados a su esparcimiento y recreación; donde se realicen espectáculos públicos culturales, deportivos u otros de similar naturaleza, tales como discotecas, cabarets, salas de eventos, cines, teatros, gimnasios, parques de entretenciones, entre otros".

Y segundo, en su artículo $5 .^{\circ}$ letra l), conceptualiza eventos masivos como

“aquellas reuniones o eventos de carácter artístico, musical, festivo, político, religioso o de otra índole, capaz de producir una concentración de 3.000 o más personas en forma simultánea”.

${ }^{6}$ Disponible en: https://www.sernac.cl/portal/604/w3-article-58216.html [Fecha de consulta: 08 de marzo de 2021]. 
A su vez, la Intendencia de la región metropolitana dictó durante el año 2015 la circular n. ${ }^{\circ} 28$, la cual en su artículo número 1 define acto masivo. $\mathrm{Al}$ igual que el Decreto del Ministerio de Salud, lo conceptualiza como aquellos donde la concurrencia sea alrededor de 3000 personas o más ${ }^{7}$ El mismo precepto, además, señala que también serán considerado eventos masivos los que, no llegando al número indicado previamente, cuenten con las siguientes características:

1) que se efectúen en lugares que no están destinados en forma permanente para la realización de eventos masivos; $y$,

2) que, por sus características específicas, requieran la adopción de medidas especiales destinadas a garantizar el orden público y/o la seguridad de los participantes, asistentes y bienes.

La Intendencia tendrá la facultad de determinar cuándo un evento masivo bajo 3000 personas requiera de medidas especiales o no, teniendo en consideración el público asistente, fecha de su realización, circunstancias climáticas o ambientales, entre otros factores.

De lo expuesto, se observa que son disposiciones de menor rango jurídico y que emanan directamente de las facultades del Ejecutivo (las cuales no pasan por la sanción o examen del poder legislativo), las que definen lo que la legislación chilena entiende por evento masivo. En consecuencia, las leyes -propiamente tal- no se han encargado de definirlo, siendo el decreto de un Ministerio y la circular de una Intendencia las que proveen una definición. De cualquier forma, y como se observará, no se está en presencia de un trabajo sistematizado en relación al tema objeto de estudio.

\section{Delimitación del objeto de estudio}

Como se indicó antes, de los eventos masivos se pueden generar varias causas que acarrean distintas consecuencias, existiendo diversos supuestos de hecho dañosos que surgen de la realización de un espectáculo público. Así, para delimitar el objeto de este trabajo, se excluirán los casos de suspensión del evento, de cambios de fecha del mismo o supuestos de modificación de artistas presentados. Tampoco se abordarán aquellos de término unilateral del contrato o la no entrega de justificante que demuestra la venta del ticket o entrada a un determinado espectáculo masivo ${ }^{8}$.

\footnotetext{
${ }^{7}$ En el mismo sentido está dirigida la resolución exenta n. ${ }^{\circ}$ 979, de 05 de marzo de 2020 de la Intendencia de la vi región del Libertador General Bernardo O’Higgins, a través de la cual aprueba reglamento para autorización de espectáculos masivos. En dicha resolución, se establece como un evento masivo aquel que convoque o pueda convocar a más de 3000 personas.

${ }^{8}$ Varias de las causales señaladas son mencionadas por la "Radiografía reclamos en el mercado de entretención" elaborada por el SERNAC. Disponible en: https://www.sernac.cl/ portal/619/w3-article-58217.html [Fecha de consulta: 08 de marzo de 2021].
} 
Si bien todas las hipótesis mencionadas antes pueden llegar a generar un detrimento al asistente, y varias de las estructuras que se propondrán pueden ser aplicables a estos hechos, lo cierto es que este trabajo se concentra sólo en determinar e indagar los alcances del incumplimiento del deber de seguridad en el consumo del proveedor que ofrece un espectáculo masivo.

\section{LOS EVENTOS MASIVOS Y LA LPC}

\section{Los eventos masivos como fenómeno de consumo}

Independiente de la conceptualización por medio de las fuentes normativas citadas, lo cierto es que, revisando la legislación chilena, se detecta que ésta se caracteriza por la ausencia de una ley propia o de un contenido normativo concreto que regule los eventos masivos de forma genérica ${ }^{9}$, ni menos el particular contrato de evento masivo que está detrás de estas situaciones ${ }^{10}$. Ello podría explicarse en función de que el mercado que rodea la compraventa de entradas para eventos masivos es de reciente

${ }^{9}$ La ley n. ${ }^{\text { }} 20844$, normativa que incorpora modificaciones al contenido de la ley n. ${ }^{\circ} 19327$-de "derechos y deberes en los espectáculos de fútbol profesional”-, establece derechos y deberes de asistentes y organizadores de espectáculos, se refiere exclusivamente a eventos relacionados al fútbol profesional.

${ }^{10}$ Por ejemplo, España es uno de los países que ha dado un tratamiento específico a la responsabilidad por daños a espectadores en eventos masivos, véase СовАCHо (2015), pp. 967-979. Adicionalmente, es preciso mencionar a la ley 19/2007 contra la violencia, el racismo, la xenofobia y la intolerancia en el deporte. Esta última en su artículo $5^{\circ}$, titulado "Responsabilidad de las personas organizadoras de pruebas o espectáculos deportivos" estipula en su párrafo $1 .^{\circ}$ que "Las personas físicas o jurídicas que organicen cualquier prueba, competición o espectáculo deportivo a los que se refiere el artículo 1 de esta Ley o los acontecimientos que constituyan o formen parte de dichas competiciones serán, patrimonial y administrativamente, responsables de los daños y desórdenes que pudieran producirse por su falta de diligencia o prevención o cuando no hubieran adoptado las medidas de prevención establecidas en la presente Ley, todo ello de conformidad y con el alcance que se prevé en los Convenios Internacionales contra la violencia en el deporte ratificados por España”. Aunque sólo contempla los espectáculos deportivos, debe ser complementada por el reglamento general de policía de espectáculos públicos y actividades recreativas, el cual fue aprobado por el real decreto 2816/1982, el cual sí se aplica a todos los eventos masivos y que establece en su artículo 51 deberes a las empresas que organicen un espectáculo masivo. De dicho precepto, cabe destacar su letra d) el cual obliga a las empresas a responder "por los daños que, en relación con la organización o como consecuencia de la celebración del espectáculo o la realización de la actividad, se produzcan a los que en él participen o lo presencien, o a otras personas, siempre que los mismos les sean imputables por imprevisión, negligencia o incumplimiento de las obligaciones establecidas en este Reglamento, y sin que el aseguramiento obligatorio de los mismos pueda excluir el carácter principal y solidario de su responsabilidad". 
data y refleja fenómenos como la contratación en masa, los contratos por adhesión, fenómenos que -por ejemplo- el Código Civil no desarrolla.

Sin perjuicio de lo señalado, es posible configurar un régimen aplicable a este tipo de escenarios en virtud de lo que consagra la LPC.

En ese sentido, cabe destacar que la LPC brinda el marco posible de aplicar a esta especial relación contractual. El artículo $1 .^{\circ}$ de la LPC establece los conceptos de consumidores y de proveedores. A los primeros los define como "las personas naturales o jurídicas que, en virtud de cualquier acto jurídico oneroso, adquieren, utilizan, o disfrutan, como destinatarios finales, bienes o servicios", mientras que a los segundos como

"las personas naturales o jurídicas, de carácter público o privado, que habitualmente desarrollen actividades de producción, fabricación, importación, construcción, distribución o comercialización de bienes o de prestación de servicios a consumidores, por las que se cobre precio o tarifa".

Este precepto se debe vincular con el artículo $2 .^{\circ}$ letra a) de la LPC que establece que quedarán sujetos a ésta los actos jurídicos que, de conformidad a lo preceptuado en el Código de Comercio u otras disposiciones legales, tengan el carácter de mercantiles para el proveedor y civiles para el consumidor. Ello, para efectos de este trabajo, se relaciona con el artículo $3 .^{\circ} \mathrm{n} .^{\circ} 8 \mathrm{del}$ Código de Comercio, el cual califica como acto de comercio los realizados por las empresas de espectáculos públicos, mientras que para el espectador este es un acto meramente civil.

Lo señalado no debe ser entendido de una forma rígida, como se analizará en el desarrollo de este trabajo, existiendo en las categorías de consumidor y proveedor más de una hipótesis de aplicación ${ }^{11}$, y extendiendo tanto a la órbita contractual como extracontractual las posibles responsabilidades.

En consecuencia, lo puntualizado lleva a establecer la LPC como un régimen aplicable a este contrato atípico de evento masivo, entendiendo en principio, al espectador como un consumidor y al organizador de eventos como un proveedor ${ }^{12}$. Esto se debe destacar dado que, en los pocos casos

${ }^{11}$ Respecto a comprender en forma más amplia el ámbito de aplicación de la LPC sin que se requiera que se haya concretado el acto de consumo (y la consecuente extensión del concepto de consumidor), véase CORRAL (2013a), pp. 110-111.

${ }^{12}$ Se debe precisar que el evento masivo del fútbol profesional ha tenido una regulación propia a través de la ley n. ${ }^{\circ}$ 19327, que establece derechos y deberes en los espectáculos de fútbol profesional. Teniendo en consideración el objetivo del presente trabajo, esta ley resulta inútil toda vez que su énfasis no está en resarcir, no enfatizando en la víctima que ha visto vulnerado su derecho a la seguridad en el consumo, sino que tiene como objetivo 
que es posible encontrar en la jurisprudencia chilena referidos a los eventos masivos, éstos se refieren a otras materias diversas al incumplimiento del deber de seguridad ${ }^{13}$ o se han canalizado a través de vías distintas a las de consumo ${ }^{14}$.

A lo descrito, se debe adicionar que, aunque la LPC es una normativa que opera de forma general y supletoria atendido su artículo $2 .^{\circ}$ bis, ésta no contiene disposiciones en lo que refiere a temas como la implementación de la responsabilidad civil contractual o extracontractual, siendo necesario acudir y aplicar al Código Civil como norma integradora y supletoria de las normas irrenunciables de la ley de consumo ${ }^{15}$ en caso de que ello sea necesario.

\section{Derechos y deberes de la LPC y eventos masivos en general}

Aplicando como sustento legal la LPC y teniendo en consideración la circular interpretativa sobre ticketeras y productoras elaborada por el SER$\mathrm{NAC}^{16}$, es posible elaborar un marco general ajustable a ambos agentes.

Como se delimitó al comienzo de este trabajo, la atención se radicará en el deber del proveedor de velar por la seguridad en el consumo, lo cual en el presente caso se vincula con escenarios donde ello se incumple en

la represión penal y la responsabilidad infraccional, habiendo una ausencia de un marco regulatorio de responsabilidad civil de los distintos actores participantes de un espectáculo. En ese sentido, las modificaciones incluidas a partir del "Plan Estadio Seguro", las cuales consagran con mayor fuerza el reproche penal, están lejos de resolver los problemas que derivan por daños a espectadores por eventos masivos. Por lo demás, sólo regula espectáculos de fútbol profesional, dejando de lado otras disciplinas deportivas u otros tipos de eventos masivos. De cualquier modo, lo anteriormente dicho debe ser complementado por el artículo $3 .^{\circ}$ de la ley n. ${ }^{\circ} 19327$, el cual, dentro de los deberes para los organizadores de eventos de fútbol profesional, establece una remisión normativa a la LPC, en razón de la cual resulta aplicable esta última también a los eventos masivos de fútbol profesional.

${ }^{13}$ Casos de eventos masivos donde se ha utilizado la LPC, pero no se refieren al incumplimiento de medidas de seguridad que acaban en daño a asistentes en eventos masivos, sino que, a casos de suspensión del evento, véase SERNAC con T4F Chile S.A. (2015); SERNAC con Ticket Fácil (2013); y, SERNAC con Producciones y Eventos Empiredigital (2012).

${ }^{14}$ Caso en que se ha acudido a las reglas de la responsabilidad extracontractual, véase V. G. C. con Club Deportivo Provincial Osorno S.A.D.P. (2012), trata de un hincha que le cae una bengala en el estadio durante la celebración de un partido, motivo por el cual decidieron interponer una demanda de indemnización de perjuicios por responsabilidad extracontractual.

${ }^{15}$ Barrientos (2014), p. 58 y Lorenzini y Polit (2013), pp. 468-472.

${ }^{16}$ Resolución exenta n. ${ }^{\circ}$ 0186, de 21 de marzo de 2019, que aprueba circular interpretativa sobre ticketeras y productoras. Disponible en: https://www.sernac.cl/ portal/618/articles-9191_archivo_01.pdf [Fecha de consulta: 08 de marzo de 2021]. 
escenarios masivos. A pesar de lo mencionado, es menester advertir que, por más que resulte lógico, el proveedor naturalmente no sólo tendrá que atender a la seguridad en el consumo, sino que también le serán aplicable todos los otros derechos y acciones resultantes del contenido tuitivo de la LPC.

Del mismo modo, el hecho que la ley tenga un carácter tuitivo, no significa que no le imponga deberes al consumidor en la relación de consumo. Particularmente en este trabajo, como se verá en los medios de exoneración, interesa el deber de autocuidado que le corresponde al espectador que asiste a un evento masivo, es decir, evitar los riesgos que puedan afectarle.

Como idea genérica, se debe señalar que estas empresas tienen el deber de respetar todos los derechos de los consumidores y le son exigibles todos los deberes contenidos en la $\mathrm{LPC}^{17}$.

\section{Partes contratantes}

El contexto a través del cual un espectador asiste a un evento masivo, infrecuentemente se caracteriza por el trato directo con la productora que organiza o produce el evento. Por regla general, esta relación estará mediada por una tercera empresa la cual se dedica a la compraventa de tickets

194 o entradas de determinados espectáculos públicos ofrecidos por diversas productoras, conocidas también como ticketeras. Por consiguiente, se está en presencia de tres partes diferentes, a saber: consumidor (asistente), proveedor intermediario (proveedor de servicios de venta de entradas para el evento) y el prestador efectivo del servicio (que vendría a ser la productora que finalmente proporciona el espectáculo público).

Del escenario presentado, cabe dilucidar qué debe hacer un espectador en caso que se haya incumplido el deber de seguridad que debe imperar durante la ejecución de la prestación. En el fondo, responder a las preguntas sobre a quién debe demandar y quiénes serían responsables por dicho incumplimiento.

a) Casos de relación entre el consumidor

y el proveedor efectivo sin intermediario

Estos casos no revisten mayor problema en atención a que es el mismo deudor quien cumple la obligación, no existiendo la relación tripartita antes mencionada. En consecuencia, no hay mayores dudas en cuanto a quién es la contraparte del consumidor en este contrato de servicios de consumo. Para esta hipótesis, el consumidor en el supuesto de que se genere

${ }^{17}$ A mayor abundamiento sobre derechos y deberes en sede de consumo, véase FERNÁNDEZ (2003), pp. 15-22. 
un incumplimiento podrá accionar directamente todos los remedios que concede la ley de consumo contra aquel proveedor que ha incumplido con su deber de seguridad en la ejecución de la prestación debida.

Luego se puntualizarán los tipos de responsabilidad en las que puede incurrir la productora de eventos o cualquier tipo de organizador de espectáculo público por incumplir con el deber de seguridad que tiene en su realización.

b) Casos de relación directa entre el consumidor y el proveedor intermediario

En esta hipótesis es posible encontrar supuestos donde el futuro asistente a un evento masivo ha celebrado un contrato a través del cual asistirá por el pago de un precio a un espectáculo, con una empresa que proporcionará o llevará a cabo dicho evento. Es decir, el consumidor y prestador efectivo son jurídicamente extraños, no existiendo relación contractual entre ambos ${ }^{18}$.

$\mathrm{Al}$ respecto, se debe destacar el artículo 43 de la LPC, el cual regula la situación de los proveedores intermediarios. Esta norma, de carácter tutelar para el consumidor ${ }^{19}$, indica que el proveedor que actúe como intermediario en la prestación de un servicio responderá directamente frente al consumidor por el incumplimiento de las obligaciones contractuales, y acto seguido, concede el derecho a repetición contra el prestador efectivo de los servicios. Ante el contenido normativo del precepto, subyace la pregunta sobre si estas empresas que median la compraventa de entradas a eventos masivos pueden ser consideradas o no como proveedores intermediarios, dado que, en esta hipótesis, la relación que importa es entre el consumidor $\mathrm{y}$ el proveedor intermediario que son quienes suscribieron el contrato.

Lo referido recientemente no es una tarea sencilla, considerando que la ley de consumo no define qué entiende por proveedor intermediario y que no hay historia legislativa clara sobre el origen del artículo $43^{20}$.

La jurisprudencia no ha sido armónica en la materia en general (en cuanto a los casos de proveedor intermediario ${ }^{21}$ ) ni en lo específico en lo que concierne a los espectáculos públicos. En ese sentido, la sentencia de la Corte de Apelaciones de Santiago, de 08 de noviembre de 2019, al responder a la pregunta sobre si la ticketera tenía la calidad de intermediario a la luz de la LPC, niega dicho carácter justificando que la empresa de tickets solamente

${ }^{18}$ Contardo (2013a), p. 904 y Córdova (2016), pp. 44-45.

${ }^{19}$ Fernández (2003), p. 63.

${ }^{20}$ Contardo (2013a), p. 901 y Córdova (2016), p. 38.

${ }^{21} \mathrm{Al}$ respecto Rodríguez (2010), pp. 698-701; Rodríguez (2014), pp. 810-812; Córdova (2016), pp. 45-50; y, Contardo (2013a), pp. 905-906. 
"se ha limitado a vender las entradas de este espectáculo y ninguna injerencia ha tenido ni ha podido tener ni en la presentación de la banda ni en la política de devolución de dinero, que obviamente la controla la productora" 22 .

En sentido contrario, existen decisiones que han entendido que el régimen aplicable a las empresas que se dedican a la venta de entradas debe ser el del artículo $43 \mathrm{LPC}^{23}$.

Ante dicha incertidumbre, más allá de los argumentos gramaticales ${ }^{24}$, adquiere relevancia atender a los argumentos jurídicos por parte de la doctrina para ir delimitando cuándo se está en presencia de un proveedor intermediario o no. En ese orden de cosas, se subraya que la sola posición de intermediario no basta para cumplir con el supuesto normativo que contiene el artículo $43 \mathrm{LPC}$, siendo necesario que quien actúe como intermediario sea también proveedor en los términos que lo exige la $\mathrm{LPC}^{25}$. Por ende, al proveedor intermediario se le exigirá, además de intermediar, los tres requisitos que ya se señalaron que exigía la LPC al proveedor, a saber:

1) que sea una persona natural o jurídica;

2) que habitualmente desarrolle prestación de servicios a consumidores; $y$,

196 3) que por ello cobre un precio o tarifa.

Aplicando lo dicho al caso particular del fenómeno de los eventos masivos, se sostiene que para averiguar si estamos en presencia o no de un proveedor intermediario -siguiendo lo sugerido por Contardo ${ }^{26}$ - es necesario comprobar que:

1) el proveedor haya celebrado un contrato de prestación de servicios con el consumidor;

2) que el proveedor cobró un precio o tarifa por el servicio contratado; $y$,

3) que el consumidor sepa, por estipulación contractual, que la ejecución de las obligaciones serán satisfechas por un tercero.

${ }^{22}$ Punto Ticket S.A con G.M.E. (2019).

${ }^{23}$ Por ejemplo: SERNAC con Ticket Fácil (2013), sentencia que fue confirmada por la Corte de Apelaciones de Santiago durante el año 2014.

${ }^{24}$ La RAE define intermediario como "adj. Dicho de un proveedor, de un tendero, etc.: Que median entre dos o más personas, y especialmente entre el productor y el consumidor de géneros o mercancías”. Disponible en:_https://dle.rae.es/intermediario [Fecha de consulta: 08 de marzo de 2021].

${ }^{25}$ Contardo (2013a), p. 902 y Córdova (2016), p. 44.

${ }^{26}$ Contardo (2013a), p. 903. En un sentido similar, Córdova sostiene que el proveedor intermediario será "aquel proveedor que celebra un contrato con el consumidor, cobrando siempre por este un precio o tarifa, cuya prestación efectiva será llevada a cabo por un tercero que no es parte en el contrato", en CóRdova (2016), p. 50. 
El mismo autor indica que lo relevante es que el proveedor cobre un precio o tarifa por la intermediación. Es en ese supuesto en el cual se está frente al supuesto de hecho contenido del artículo 43 LPC.

En los eventos masivos, además de que estas empresas intermediadoras cobran un precio por su servicio, los consumidores o asistentes saben que la prestación de servicios será satisfecha por una empresa que no es la misma con la cual han comprado el ticket ${ }^{27}$. Lo anterior queda claro en casos como el fútbol (las tres partes integrantes serían hincha, empresa de ticket y sociedad anónima detrás del equipo de fútbol) o los conciertos (la tríada se conformaría por fan, empresa de ticket y productora que trae al artista), donde es posible visibilizar con mayor nitidez los requisitos exigidos. Así también lo ha entendido el SERNAC, como queda demostrado con su circular interpretativa para mercado de ticketeras $^{28}$ y también durante 2019, donde ha interpuesto una demanda colectiva en contra de una empresa productora del evento como de la ticketera en su calidad de proveedor intermediario ${ }^{29}$.

Por tanto, en caso de que se cumplan los requisitos señalados, el asistente podrá demandar directamente a la empresa que media la compraventa de entradas, sin perjuicio de los derechos de repetición que tiene el proveedor intermediario en contra del prestador efectivo del servicio.

\section{c) Consumidor jurídico y consumidor material}

Tal como se ha hecho la distinción entre los distintos tipos posibles de proveedores, se debe realizar la misma operación en lo que concierne a los consumidores.

Momberg sostiene que la definición de consumidor del artículo $1 .^{\circ} \mathrm{n} .^{\mathrm{o}} 1$ LPC admite

\footnotetext{
${ }^{27}$ En igual sentido, Córdova indica que la aplicación del artículo 43 LPC a las ticketeras es correcta, pues "habría intermediación en el sentido que se ha estudiado toda vez que el consumidor celebra un contrato con la compañía ticketera, por el cual paga una tarifa, pero con expreso conocimiento que la realización del evento será efectuada por un tercero ajeno al contrato: la productora". CóRdOva (2016), pp. 48-49.

${ }^{28} \mathrm{Al}$ respecto, el SERNAC indica que las "empresas de venta de entradas adquieren la calidad jurídica de proveedor ya sea, por el desarrollo de su propio negocio como por la calidad de intermediario que adoptan o que deben adoptar para el desarrollo de aquel. En el referido escenario, la responsabilidad de estas empresas para con el público consumidor, también tiene su fundamento legal en el artículo 43 de la Ley n. ${ }^{\circ} 19.496$, toda vez que no son sino aquellas, quienes aparecen enfrentando la relación de consumo en representación del directo prestador del servicio y, quien ha asumido el rol de vender por aquel, las entradas para un determinado espectáculo, evento deportivo, musical u otro". Servicio Nacional del Consumidor (2019), p. 10.

${ }^{29}$ Presentada ante el $18 .^{\circ}$ Juzgado Civil de Santiago, rol n. ${ }^{\circ}$ C-9643-2019, caratulado SERNAC con Punto Ticket S.A.
} 
"que se trate no sólo de personas ligadas por vínculos contractuales, sino por cualquier acto jurídico oneroso, incluyendo la mera utilización o disfrute del bien o servicio" ${ }^{30}$.

De lo mencionado, subyace la distinción entre consumidor jurídico y material. Los primeros son los que compran o adquieren determinados bienes y servicios, mientras que los segundos son los que utilizan o disfrutan dichos bienes o servicios ${ }^{31}$. Así, por ejemplo, A le regala dos entradas a $\mathrm{B}$ y $\mathrm{C}$ para que vayan a ver a $\mathrm{X}$. En el ejemplo, A sería consumidor jurídico y $\mathrm{B}$ con C serían consumidores materiales. En el caso de los eventos masivos, es simple distinguir quiénes serían unos y otros.

Aunque en su oportunidad se criticó a los tribunales por cierto formalismo y no tener en consideración la visión tuitiva ${ }^{32}$ de la ley que protege los derechos del consumidor ${ }^{33}$, lo cierto es que, en la actualidad, ambos tipos de consumidores tienen el derecho a solicitar la indemnización de

${ }^{30}$ Momberg (2013), p. 6.

${ }^{31}$ Barrientos (2019), p. 8. En igual sentido, Momberg (2013), p. 7.

${ }^{32}$ En el mismo sentido, el Tribunal Constitucional, en su fallo a propósito del requerimiento de inaplicabilidad presentado por Universal Agencia de Turismo Limitada, 198 respecto del artículo 43 de Ley 19496, sobre protección de los derechos de los consumidores, en causa rol n. ${ }^{\circ}$ 4898-2007, de la Corte de Apelaciones de Santiago, señaló en su considerando 9..$^{\circ}$ que: "el denominado Derecho de Protección al Consumidor constituye una moderna rama del Derecho Privado, de clara impronta social, cuyo objeto es regular las relaciones jurídicas de consumo, entendidas por tales las que se anudan entre proveedores profesionales de bienes o servicios y los consumidores finales de tales satisfactores. Dicha normativa se funda en la constatación de las desigualdades o asimetrías presentes en la relación de consumo entre una y otra parte, principalmente traducidas en su diferente nivel de información sobre los bienes o servicios a contratar, en su dispar capacidad negocial y en las distintas dificultades que enfrentan al momento de hacer efectivos sus respectivos derechos, por ello es que el legislador, en este ámbito de regulación, se ha orientado por un predicamento tuitivo de los intereses de la parte más débil o desfavorecida de la relación jurídica, vale decir, el consumidor, lo que imprime a esta normativa un marcado sello protector o tutelar, y de allí la denominación que ha recibido como disciplina jurídica”.

${ }^{33}$ En un primer momento no se consideraban por parte de los tribunales a los consumidores materiales dentro del ámbito de protección de la LPC. Al respecto, Barrientos (2015), pp. 333-350. Como advierte Fuenzalida, a propósito de la aplicación de la ley al consumidor material, "Si permanecemos esclavos a lo prescrito en la definición legal sin hacernos cargo de una análisis sistemático del conjunto de la Ley, obviando principios fundamentales como la confianza impresa por el proveedor en su oferta a persona indeterminada y el derecho a la seguridad que tiene el consumidor expresamente establecido en la Ley, llegaremos al absurdo de que una persona por el solo hecho de no comprar un bien o servicio, estará desprotegida por la Ley $\mathrm{N}^{\circ} 19.496$, lo que resulta una injustificada restricción”. Fuenzalida (2018), p. 132. En igual sentido, Hernández y Gatica defienden una noción amplia de consumidor, de forma tal que la LPC brinde protección al consumidor jurídico, pero también al material. HERNÁNDEZ y GATICA (2019), pp. 23-27. 
perjuicios por ver vulnerada la seguridad en el consumo del servicio que han contratado. Como afirma Fuenzalida, en el acto del consumo merece protección todo aquel sujeto que está expuesto a la situación de consumir ${ }^{34}$.

\section{El contrato de eventos masivos: concepto, características y problema}

La falta de regulación de esta materia en específico hace necesario esbozar un concepto y algunas características del contrato en cuestión. Toda persona que compra un boleto o entrada para un evento masivo está celebrando un contrato de consumo, ya sea con la productora que gestiona dicho evento de forma directa o con una empresa que es intermediadora del servicio ofrecido. En virtud de esta convención, el proveedor se compromete a proporcionar un espectáculo -facilitando las comodidades y la seguridad para el disfrute del mismo- a cambio del pago de un precio por parte del segundo. Definir de este modo el contrato es funcional, toda vez que lo entiende como un contrato de consumo y comprende a la seguridad como un elemento trascendente en la configuración del mismo.

A la definición se le debe entender integrada la noción amplia de consumidor previamente dada en función de la finalidad protectora de la ley del consumo, ergo, se debe incluir tanto a quien compra una entrada para un evento masivo, como a todo aquel que va a disfrutar del mismo.

Del mismo modo, es menester señalar ciertos atributos que están presentes en este tipo de contratos. $\mathrm{Al}$ ser entendido como un contrato de consumo, existen algunas diferencias con la regulación de otros países. No obstante, ello no es óbice para apoyarse -en parte- en lo señalado por la doctrina extranjera ${ }^{35}$, sobre todo apreciando la escasa atención que ha recibido este tema por parte de la doctrina nacional. En consecuencia, las características son tres.

En primer lugar, es de servicios, pues el proveedor se compromete a una prestación determinada por el pago de una entrada. Este tipo de contratos se distingue por engendrar obligaciones de hacer ${ }^{36}$, como puede ser la realización de un determinado espectáculo de diversa índole en este caso. Además, es de servicios a consumidores, siendo aplicable el estatuto de la LPC.

En segundo lugar, es oneroso (artículo 1441 Código Civil) toda vez que supone una contraprestación a cumplir por ambas partes, y existe utilidad

${ }^{34}$ Fuenzalida (2018), p. 132.

${ }^{35}$ Así, por ejemplo, se observan las características que propone CASADO (2015), quien se refiere a este tipo de contrato a propósito de espectáculos deportivos. Sin perjuicio de no decidirse en sede de consumo estas materias en España, a nuestro juicio, las apreciaciones de la autora son plenamente aplicables a cualquier contrato de evento masivo, pp. 375-376.

${ }^{36}$ Rodríguez (2014), p. 794 y Mejías y Brantt (2018), pp. 590-591. 
para ambos contratantes ${ }^{37}$. Con la celebración del contrato, por un lado, está la ganancia para la productora y, por otro lado, la posibilidad de asistir a un espectáculo masivo para el espectador ${ }^{38}$. Esto debe ser complementado por la comprensión literal del artículo $1 .^{\circ} \mathrm{LPC}$ en sus numerales $10^{\circ}$ y $2 .^{\circ}$ que indican que el contrato de consumo es una convención onerosa. Si bien la onerosidad del contrato no está en duda, ello debe ser complementado con la noción amplia de consumidor dada previamente, de forma tal que la LPC no incluye exclusivamente las relaciones que participa el consumidor jurídico sino que también se extiende al consumidor material ${ }^{39}$.

En tercer lugar, es por adhesión debido a que el proveedor es quien establece las condiciones, por lo que el espectador que asiste al espectáculo masivo sólo acepta éstas al comprar las entradas. En estos supuestos, las cláusulas han sido propuestas unilateralmente por el proveedor sin que el consumidor, para celebrarlo, pueda alterar su contenido (artículo $10^{\circ} \mathrm{n} .^{\circ} 6$ LPC). Cabe advertir, que más que proposición como señala la ley, en el contrato de adhesión existe una imposición del contenido contractual por parte de uno de los contratantes al otro ${ }^{40}$. De esta manera, el rasgo decisivo de la adhesión se encuentra en el desequilibrio del poder negociador de los contratantes, producto de que es obra exclusiva del oferente. En contrapartida, el destinatario, siendo el más débil, no puede discutir la oferta y debe limitarse a aceptarla ${ }^{41}$. En razón de las circunstancias expuestas, emerge el contenido tuitivo de la LPC proporcionando protección al asistente a un espectáculo masivo. Por tanto, se debe vincular dicho contenido protector con este tipo de contrato atípico.

A pesar de que la definición y las características de este contrato particular contribuyen a aproximarse a la problemática desde un punto de vista contractual, lo cierto es que de la realidad de los eventos masivos surge el problema que en la mayoría de los casos no se tiene como proveedor a quien va a organizar y llevar a cabo el espectáculo de alta convocatoria. A lo

${ }^{37}$ Abeliuk (2008), tomo I, p. 77.

${ }^{38} \mathrm{Al}$ respecto, interesante resulta el planteamiento de Piñeiro, quien -a propósito de los espectáculos masivos deportivos en España- indica que en los eventos masivos gratuitos el espectador asume más riesgos que en un evento oneroso, dado que "se entiende que si existe un organizador que se lucra de la actividad también tiene que velar con mayor celo por la seguridad de los espectadores o, lo que es lo mismo, que la compra de la entrada por parte del espectador es un contrato atípico de exhibición deportiva que obliga al organizador a velar por la seguridad de los espectadores", en PiñeIro (2005), p. 13. Por su parte, autores argentinos sostienen que "la existencia o inexistencia de un lucro, sea un espectáculo deportivo o de otra índole, no puede ser -creemos- determinante para imponer o desligar la responsabilidad de resarcir un daño". EChevesti y Zudaire (2018), p. 392.

${ }^{39}$ Hernández y Gatica (2019), p. 23.

${ }^{40}$ Maldonado (1998), p. 168.

${ }^{41}$ Abeliuk (2008), tomo I, pp. 92-93. 
dicho, sin perjuicio de la definición proporcionada del contrato de eventos masivos, se debe sumar que este tipo de contratos infrecuentemente prevé cuestiones relativas a la indemnidad de los espectadores o el resguardo de los mismos, regulando otros aspectos de esta relación jurídica.

Este diagnóstico conduce a cuestionarse si la existencia de un contrato determina que ésta sea la vía por la cual el consumidor actuará en casos en que no se hayan adoptado las medidas de protección adecuadas en la ejecución de un evento masivo.

Para autores como Hernández y Gatica, los deberes de seguridad están fuera de las obligaciones generadas por la convención, por lo que estiman conveniente la aplicación del estatuto extracontractual ${ }^{42}$. Por su parte, autoras como Isler ${ }^{43}$ o Barrientos ${ }^{44}$ sostienen que, en casos de infracción a la LPC e incumplimiento contractual, se presentará un concurso de acciones donde será el legitimado activo quien optará entre el régimen contractual o extracontractual de la responsabilidad civil. En hipótesis de eventos masivos, esto se traduciría en que el espectador que ha comprado su entrada tendrá un derecho de opción para perseguir la responsabilidad del organizador que deriva de la no adopción de medidas de seguridad correspondiente en espectáculos públicos.

En este trabajo se estima que se debe optar por la aplicación del estatuto extracontractual para este tipo de supuestos según se desarrollará en el capítulo sobre las responsabilidades en las cuales puede incurrir el proveedor, el cual tiene mayor asidero en la jurisprudencia nacional en materias de consumo vinculadas con el deber de seguridad ${ }^{45}$. Aun cuando es posible erigir una solución contractual a través del principio de buena fe, el cual tiene alcance general ${ }^{46}$ y por tanto se aplica a todos los actos o negocios jurídicos, pudiendo fundamentar los deberes de conducta que sirven al mejor cumplimiento de las prestaciones contenidas en el contrato (entre ellos podría ser el de la seguridad en eventos masivos $)^{47}$, se ha priorizado la protección de la tutela aquiliana. La preferencia por este estatuto es sin perjuicio del reconocimiento del derecho de opción que tiene el consumidor en este tipo de casos.

${ }^{42}$ Hernández y Gatica (2019), p. 33.

${ }^{43}$ ISLER (2015), p. 12.

${ }^{44}$ Barrientos (2012), p. 413

${ }^{45}$ A propósito de un estudio sobre la función del artículo 23 LPC como fuente ambigua de responsabilidad, Barrientos sostiene que, en la práctica, el principio de la primacía del contrato ha perdido vigencia y se ha dado paso a la aplicación principalmente del estatuto extracontractual. Véase BARRIENTOS (2012), p. 414.

${ }^{46}$ Sobre este tema Eyzaguirre y Rodriguez (2013), p. 148 y ss. y Boetsch (2011), p. 46 y ss.

${ }^{47}$ FACCO (2009), pp. 152-153. 


\section{EL INCUMPLIMIENTO DEL DEBER DE SEGURIDAD}

EN EL CONSUMO EN EVENTOS MASIVOS

Corresponde indagar, ahondar en concreto, sobre la idea de seguridad presente en los eventos masivos, su fundamento y las implicancias que ésta tiene y el correspondiente derecho a la indemnización que genera su incumplimiento.

\section{El derecho y el correlativo deber que surgen de la seguridad en el consumo y su relación con los eventos masivos}

El artículo $3 .^{\circ}$ inciso $1 .^{\circ}$ letra d) LPC consagra tanto el derecho a la seguridad en el consumo de bienes o servicios (además de la protección de la salud y el medio ambiente). Este derecho, que tiene por objeto resguardar la integridad del consumidor, posee también reconocimiento constitucional en el catálogo de derechos consagrados en el artículo 19, particularmente en sus numerales $10^{\circ}$ (derecho a la vida y a la integridad física y psíquica de la persona) y $9 .^{\circ}$ (derecho a la protección de la salud $)^{48}$. La norma aludida debe ser entendida como un derecho subjetivo fundamental sobre el cual se edifica todo el resto de la disciplina legal ${ }^{49}$, es decir, no se está en

202 presencia de una mera declaración de intenciones, sino que se trata de una norma que su infracción acarrea toda la batería de acciones y remedios que concede la ley de consumo.

Adicionalmente, esta disposición se ve reafirmada en distintos pasajes de la LPC y sirve de interpretación de normas como el artículo 23 LPC $^{50}$, la cual, como se verá, tiene especial trascendencia al momento de abordar la responsabilidad por el incumplimiento del deber de seguridad en el consumo en la realización de actos masivos. En específico, el artículo 23 inciso $1 .^{\circ}$ estipula que se cometerá infracción a las disposiciones de la LPC, entre otros casos, en la hipótesis de que se desarrolle un servicio negligente debido a fallas de seguridad del mismo.

En contrapartida a este derecho, estará el deber de la empresa productora de eventos, proveedora en esta relación de consumo, de contar con las autorizaciones administrativas correspondientes que garanticen un espectáculo seguro, así como garantizar que las entradas vendidas correspondan a la capacidad real del recinto, entre otras cuestiones. Por consiguiente, dentro de ese deber estará el hecho de que el evento masivo se desarrolle según lo previsto, esto es, que el prestador del servicio haya adoptado todas

\footnotetext{
${ }^{48}$ ISLER (2019), pp. 228-229.

${ }^{49}$ Corral (2013a), p. 109.

${ }^{50}$ Corral (2013a), p. 110.
} 
las medidas de resguardo correspondientes para la correcta ejecución de la prestación debida. Como señala la doctrina extranjera, en principio, los espectadores no asumen riesgos, puesto que quien acude a presenciar un espectáculo masivo lo hace con la confianza de que el organizador habrá adoptado las medidas de seguridad necesarias, es decir, que garantizarán su normal desarrollo y disfrute sin riesgo alguno para las personas del público ${ }^{51}$. Sin embargo, cabe cuestionarse los pormenores que implican esta obligación en materia de espectáculos públicos y el contenido del mismo, de modo de ir comprendiendo en qué supuestos se produce su incumplimiento.

En ese orden de cosas, se debe resaltar que la doctrina ha omitido este tema (en lo que refiere espectáculos públicos en específico) y son pocas las decisiones de los tribunales chilenos sobre el deber de seguridad en eventos masivos desde la perspectiva del consumo. No obstante, es posible mencionar algunos fallos.

$\mathrm{Al}$ respecto, la sentencia dictada por el $16 .^{\circ}$ Juzgado Civil de Santiago, la cual resolvió una controversia que relaciona el deber de seguridad con la celebración de un evento masivo. En concreto, el tribunal tuvo que resolver el litigio a propósito de un evento denominado "Zombie Escape 5K". En la resolución señalada, se determinó que la empresa proveedora infringió el deber de seguridad establecido en el artículo $3 .^{\circ}$ de la LPC, aludiendo a la

"la insuficiencia e inidoneidad del personal de seguridad contratado, la insuficiencia de asistencia médica comprometida, la exposición de los participantes a vehículos y animales dentro de la zona establecida para la corrida, la insuficiencia de baños sanitarios en relación con la cantidad de participantes, y el deficiente sistema de custodia o guardarropía que se puso a disposición de los participantes" ${ }^{52}$.

En igual sentido, el Primer Juzgado de Letras de Osorno condenó a la empresa Latin Gaming Osorno S.A. por infringir el derecho a consumir bienes y servicios en un ambiente de seguridad. Específicamente, se responsabilizó a la demandada en atención a lo tutelado en el artículo $3 .^{\circ}$ inciso $1 .^{\circ}$ letra d) LPC por no adoptar

"las medidas para evitar cobrar entradas que superaran la capacidad del edificio y, consiguientemente, para impedir circunstancias que constituyeran riesgo para los consumidores, tales como altercados, conflictos, peleas o desórdenes" ${ }^{53}$.

${ }^{51} \mathrm{Al}$ respecto, véase MEdina (2004), p. 256; PiñeIro (2005), p. 10; y, QUeSAdA (2009), p. 29.

${ }^{52}$ SERNAC con Sach Producciones y Eventos Ltda. (2017).

${ }^{53}$ SERNAC con Latin Gaming Osorno S.A. (2014). 
De las decisiones expuestas, se puede afirmar que, dentro del deber de seguridad, la idea de que la actividad se despliegue sin riesgos que puedan afectar a los asistentes es fundamental. En concreto, el no exponer a riesgos innecesarios a los consumidores por parte de los proveedores conlleva varias obligaciones que no se encuentran en otro tipo de servicios. Por tanto, además de las medidas administrativas y sanitarias pertinentes, será importante -por ejemplo- observar la dotación suficiente de guardias de seguridad y prever la extensión de horas que deberán soportar los mismos para determinar si se requieren más personal o no; si el lugar del evento permite un control en los accesos (lo cual puede hacer vulnerable el espacio para la entrada clandestina de personas), e ingresos de drogas y alcohol ${ }^{54}$.

Constatado el escaso pronunciamiento por parte de la magistratura, una buena herramienta para considerar los alcances de este deber de seguridad en los eventos masivos, es complementarlo con lo que se ha dicho sobre el mismo en otras circunstancias. En este aspecto, siguiendo un informe de jurisprudencia sobre este deber en materias de consumo ${ }^{55}$ es posible dar ciertas luces al respecto. Por un lado, será importante contar con servicios de primeros auxilios para responder de forma adecuada ante potenciales riesgos que conlleva la masividad ${ }^{56}$. Por otra parte, el hecho de que la empresa de eventos masivos adopte un estándar de control de calidad exigente, no hace que cualquier descuido se considere un caso fortuito ${ }^{57}$. De igual forma, se deben adoptar las medidas de resguardo necesarias para que el evento se realice en adecuadas condiciones de seguridad ${ }^{58}$. Así también, la posibilidad de que se genere un daño en un evento masivo también incluye sus inmediaciones ${ }^{59}$.

Todos los elementos mencionados por la jurisprudencia en otras circunstancias sobre este deber pueden ser valorados al momento de configurar el contenido de éste en el caso concreto. Del mismo modo, se puede acudir a la doctrina de otras latitudes donde se ha escrito del tema, destacando que los proveedores deben velar por el acotamiento de zonas, las advertencias y prohibiciones dirigidas al público ${ }^{60}$; adoptar las medidas adecuadas para

${ }^{54}$ Estas ideas se extraen de la lectura de la sentencia de SERNAC con Punto Ticket S.A. (2019), la cual se refiere a un oficio emitido por la Intendencia de Santiago que fue presentado como prueba.

${ }^{55}$ UlloA (2014), pp. 1-39.

${ }^{56}$ Caso a propósito de caída de objetos desde altura a consumidor en UlLOA (2014), p. 8.

${ }^{57}$ Caso a propósito de un trozo de metal en hamburguesa en UlloA (2014), p. 36.

${ }^{58}$ Caso de caída desde altura de consumidor que se encontraba sobre una escala telescópica, UlLOA (2014), p. 38.

59 A propósito de casos de responsabilidad del mall como arrendadora de locales comerciales, UlloA (2014), p. 17. Por ejemplo, en Argentina a propósito de un espectáculo público deportivo, véase Echevesti y Zudaire (2018), p. 390.

${ }^{60}$ YzQuierdo (2008), vol. 2, p. 1841. 
prevenir daños de la aglomeración de muchas personas en un mismo lugar, como pueden ser las avalanchas humanas ${ }^{61}$; constatar el buen estado de las instalaciones del recinto no pudiendo desligar su responsabilidad por un daño que se explique por dicha causa ${ }^{62}$; y velar por el cumplimiento por parte de los asistentes de las condiciones de acceso y permanencia en el recinto (prohibir la introducción de armas, acceso sin entrada o bajo la influencia de drogas ${ }^{63}$.

Este marco debe ser completado por lo estipulado en algunas normas propias del ordenamiento jurídico chileno. A modo de referencia, la ley 19327 que establece derechos y deberes en los espectáculos de fútbol profesional, en su artículo $2 .{ }^{\circ}$ letras b) y c) estipula que el asistente tiene el derecho a la seguridad. En específico, la letra b) señala que tendrá derecho a que los espectáculos cumplan con condiciones básicas de higiene, seguridad y salubridad, mientras que la letra c) consagra el derecho a contar con información oportuna sobre las condiciones básicas de seguridad en el espectáculo, sobre las medidas de prevención y protección de riesgos inherentes a la actividad, y todas las medidas técnicas necesarias y suficientes que los organizadores, dentro de su esfera de control, deban adoptar con dicho propósito. La misma normativa en su artículo $3 .^{\circ}$ expresa el deber que tiene el organizador del evento de satisfacer la seguridad en la realización del mismo ${ }^{64}$. Si bien esta ley solamente se refiere a eventos masivos relacionados con el fútbol -de hecho, contiene una remisión normativa a la LPC-, es un buen ejemplo para demostrar lo relevante de los resguardos en la ejecución de un espectáculo, entendiéndose como parte esencial en la celebración del mismo.

En suma, valorando los elementos aportados, la finalidad tuitiva de la ley que protege los derechos de los consumidores y las características propias a la producción de un evento masivo, puede decirse que la seguridad es un elemento inherente a la prestación del servicio que debe ser colmado de contenido. El espectador que asiste a un evento masivo tiene la

${ }^{61}$ Seligrat (2016), p. 271.

${ }^{62}$ Seligrat (2016), p. 277.

${ }^{63}$ Así lo afirma en España autoras como Casado (2018), p. 6 y en Argentina autores como Echevesti y Zudaire (2018), p. 389.

${ }^{64}$ En concreto, el artículo $3 .^{\circ}$ señala entre los deberes del organizador el organizar y administrar el espectáculo deportivo adoptando todas las medidas necesarias y las exigidas para el correcto desarrollo del mismo (letra a); supervisar y garantizar el cumplimiento de la ley, su reglamento y las disposiciones que la autoridad administrativa o policial le hayan ordenado adoptar (letra b); adoptar las medidas de seguridad establecidas en las leyes, reglamentos, disposiciones de la autoridad y protocolos determinados por la entidad superior del fútbol profesional, necesarias para prevenir alteraciones a la seguridad y al orden público que sean producto del espectáculo deportivo de fútbol profesional, hecho o actividad conexa, tales como venta de entradas (letra c). 
legítima expectativa al asistir a un recital o una actividad deportiva -entre otras muchas variantes de espectáculos públicos- de no sufrir daños en el mismo, constituyéndose así la seguridad en el consumo como una cuestión trascendente ${ }^{65}$.

\section{Derecho a la reparación e indemnización adecuada y oportuna en los eventos masivos}

El artículo $3 .^{\circ}$ inciso $1 .^{\circ}$ letra e) de la LPC señala que el consumidor tiene derecho a la reparación e indemnización adecuada y oportuna de todos los daños materiales y morales en caso de incumplimiento de cualquiera de las obligaciones contraídas por el proveedor. Este precepto se modificó el año 2004 por la ley 19955, sustituyéndose la expresión "en caso de incumplimiento a lo dispuesto en esta ley" por la nueva "en caso de incumplimiento de cualquiera de las obligaciones contraídas por el proveedor". Con tal alteración, debe entenderse que existe una ampliación del espectro indemnizatorio, extendiéndose ya no sólo a la ley sino que también a lo que refiere el contrato ${ }^{66}$.

Así también, la norma aludida debe ser vinculada con el derecho a la seguridad toda vez que se ha entendido que el mencionado derecho 206 a reparación por sí solo no tiene un poder para ejercer la reparación e indemnización en contra de un proveedor ${ }^{67}$, siendo necesaria la violación a otras normas de la LPC. Por consiguiente, la normativa de consumo le impone un deber de resguardo que debe estar presente en la forma en que el proveedor ofrece y ejecuta los respectivos servicios, de manera tal que los consumidores siempre tengan en contra de quien hacer efectiva las posibles responsabilidades que surjan de las infracciones del contenido que prescribe la LPC.

Otro punto a considerar es que, de la lectura del artículo, se desprende que concede tanto un derecho a la reparación como a la indemnización. Parte de la doctrina ha sostenido que, por un lado, la reparación refiere a todos los remedios distintos a la indemnización de perjuicios (v. gr., la garantía legal, la nulidad del contrato por cláusulas abusivas, entre otros),

${ }^{65}$ Por ejemplo, interesante es el planteamiento de Marcelo Barrientos, quien a propósito de la relación de consumo que se genera a partir de los estacionamientos, señala que "A estos elementos, propios del contrato de estacionamiento, cabría agregar el de la legítima expectativa del usuario de recobrar su automóvil tal y cual lo dejó al estacionarlo. Estimamos que ello se traduce en una verdadera obligación de seguridad que aparece como esencial al contrato mismo de estacionamiento regido por la 'Ley del consumidor'". BARRIENTOS (2010), p. 48.

${ }^{66}$ Fuenzalida (2018), p. 126.

${ }^{67}$ Contardo (2013c), p. 119. 
mientras que, por otro lado, la indemnización de perjuicios debiese ser entendida en su sentido tradicional de reparar los detrimentos que ha sufrido la víctima ${ }^{68}$.

Cabe puntualizar que el artículo $3 .^{\circ}$ inciso $1 .^{\circ}$ letra e) LPC ha sido comprendido como el reconocimiento legal expreso en materias de consumo del derecho del consumidor a perseguir la responsabilidad civil del proveedor, cuando ha sufrido daños y perjuicios en el marco de la LPC ${ }^{69}$. Este precepto debe ser relacionado con el artículo 23 de la LPC, el cual además de una responsabilidad infraccional, se ha entendido que prevé una responsabilidad civil $^{70}$. Cabe complementar lo informado con lo que prescribe el artículo $43 \mathrm{LPC}$, el cual concede la posibilidad de perseguir la responsabilidad civil del proveedor intermediario en el contrato de evento masivo, en casos de incumplimiento de la obligacionales contractuales ${ }^{71}$, entre ellas la de seguridad.

Según lo estudiado, aun cuando esto se abordará con mayor detalle en el siguiente acápite, vinculando este derecho con los supuestos de eventos masivos, es posible afirmar que el asistente que ha sufrido una vulneración a su derecho a la seguridad en el consumo, también posee un derecho a la reparación e indemnización tanto contra el proveedor efectivo e intermediario. En consecuencia, de esta situación emerge la posibilidad para el consumidor de perseguir las responsabilidades correspondientes por la infracción del deber de seguridad por parte del proveedor que ofrece espectáculos públicos.

\section{RESPONSABILIDADES \\ EN LAS QUE PUEDE INCURRIR EL PROVEEDOR DE EVENTOS MASIVOS}

Revisando las reglas de la LPC, aunque el tratamiento de la responsabilidad no se caracteriza por su sistematicidad ${ }^{72}$, es posible afirmar que las responsabilidades en las que puede incurrir el organizador de evento masivo podrán ser de dos tipos: civil e infraccional. Para profundizar en este

${ }^{68}$ Contardo (2013c), p. 122. En el mismo sentido, Fuenzalida (2018), p. 140.

${ }^{69}$ Contardo (2013c), p. 122.

${ }^{70}$ BARrientos y Contardo (2013), p. 581. Por su parte, Isler defiende la idea de que todas las normas de esta ley pueden dar origen indistintamente a la acción civil e infraccional, en IsLER (2015), pp. 7-12.

${ }^{71}$ Contardo (2013a), p. 900.

${ }^{72}$ Corral (1999), p. 169. Indica también la falta de sistematicidad FuenZalida (2018), p. 126. Por su parte, Isler indica que respecto a la responsabilidad civil e infraccional en la ley de consumo "no existe claridad respecto de las disposiciones de este cuerpo normativo que da origen a cada una de ellas", en IsLer (2015), p. 2. 
tópico, se debe distinguir entre si estamos en presencia de un proveedor intermediario o es directamente con el prestador que ejecuta la prestación, pues el régimen de responsabilidad tiene distintos matices según trate de uno o de otro supuesto.

\section{Responsabilidad en casos de relación consumidor $y$ proveedor que ejecuta la prestación sin intermediario}

\section{a) Fundamento de responsabilidad}

Atendido el contenido de la LPC, la responsabilidad del proveedor se puede configurar de la siguiente manera. Por un lado, está el artículo $3 .^{\circ}$ inciso $1 .^{\circ}$ letra e), que, como se revisó, configura en favor de los consumidores el derecho a la indemnización adecuada y oportuna de todos los daños materiales y morales en caso de incumplimiento de cualquiera de las obligaciones contraídas por el proveedor, y el deber de accionar de acuerdo a los medios que la ley le franquea. Por otro lado, la normativa citada se debe relacionar con lo establecido en el artículo 23 inciso $1 .^{\circ} \mathrm{LPC}$, el cual se ha entendido que comporta una responsabilidad civil derivada de la responsabilidad infraccional establecida en el mismo precepto ${ }^{73}$. Concretamente, la norma establece que cometerá infracción a las disposiciones de la LPC 208 el proveedor que, en la venta de un bien o en la prestación de un servicio, actuando con negligencia, cause menoscabo al consumidor debido a fallas o deficiencias en la calidad, cantidad, identidad, sustancia, procedencia, seguridad, peso o medida del respectivo bien o servicio.

Cabe añadir que la doctrina ha reflexionado sobre el carácter ambiguo del artículo 23 como fuente de responsabilidad en la LPC. Al respecto, se adhiere a lo que expone Barrientos, quien sostiene que la infracción al artículo 23 inciso $1 .^{\circ} \mathrm{LPC}$, además de la responsabilidad infraccional, genera una concurrencia u opción de responsabilidad civil donde "el juez elegirá la vía de solución más apta para el consumidor, que en la mayoría de los casos será la extracontractual"74.

Lo explicado debe ser complementado por lo expresado en el artículo 50 inciso $2 .^{\circ}$ de la misma ley, que indica que el incumplimiento de las normas contenidas en LPC, dará lugar a las denuncias o acciones correspondientes, destinadas a sancionar al proveedor que incurra en infracción, y entre ellas está el obtener la debida indemnización de perjuicios o la reparación que corresponda. Siguiendo a Baraona, quien tiene un trabajo comparativo entre las reglas de la LPC y el Código Civil, una marcada diferencia entre ambos cuerpos normativos es en materia de la responsabilidad

${ }^{73}$ Barrientos y Contardo (2013), p. 558.

${ }^{74}$ Barrientos (2012), p. 421. 
civil derivada del incumplimiento de un contrato, siendo determinante en el contrato de consumo que se haya incumplido por parte del proveedor algunas de las prescripciones de la $\mathrm{LPC}^{75}$.

De esta forma, una vez vulnerado el derecho a la seguridad en el consumo de los consumidores, es decir, una vez que los asistentes sean expuestos a situaciones de peligro o daño por falta de medidas de cuidado adoptadas, los mismos tienen derecho a exigir la responsabilidad civil de los proveedores con fundamento en la normativa citada previamente.

\section{b) Sobre la responsabilidad civil}

Existe una discusión académica sobre si toda infracción a la LPC genera a su vez responsabilidad civil. Por una parte, la tesis unitaria, quienes entienden que de todas las normas de la LPC pueden dar origen indistintamente a la acción civil e infraccional ${ }^{76}$; y, por otra, una tesis que reclama la diferenciación de las contravenciones ${ }^{77}$. Esta discusión pierde relevancia al vincularlo con el artículo 23 inciso $1 .^{\circ}$, dado que, independiente de cual sea la tesis defendida, se ha entendido que integra ambas acciones (civil e infraccional).

Una vez aclarado lo anterior, cabe cuestionarse sobre las exigencias existentes a la responsabilidad civil que deriva de la infracción del artículo 23 inciso $1 .^{\circ}$ LPC.

En ese escenario, se ha indicado que una ventaja que existiría, de asumir que la responsabilidad civil deriva de la responsabilidad infraccional en el caso del artículo 23 inciso $1 .^{\circ} \mathrm{LPC}$, es que al establecer la segunda antes que la primera se establece la llamada culpa contra la legalidad o culpa infraccional, la cual supone probada la culpa con la mera infracción ${ }^{78}$. Esto se fundamentaría en el artículo 14 de la ley 18287, que establece el procedimiento ante los Juzgados de Policía Local, el cual estipula que

"el solo hecho de la contravención o infracción no determina necesariamente la responsabilidad civil del infractor, si no existe relación de causa a efecto entre la contravención o infracción y el daño producido".

De esta forma, el consumidor se vería beneficiado, pues sólo se le exige acreditar el daño y la causalidad mas no así la culpa. Esta interpretación no debe ser entendida en el sentido de que la responsabilidad civil sea una consecuencia inmediata y directa de la responsabilidad contravencional,

\footnotetext{
${ }^{75}$ Baraona (2014), p. 397.

${ }^{76}$ ISLER (2015), pp. 1-17.

${ }^{77}$ Guerrero (2008), pp. 433-453.

${ }^{78}$ Barrientos y Contardo (2013), p. 558.
} 
sino que como una lectura de ambos estatutos independientes en beneficio y protección del consumidor, el cual es la parte débil en este tipo de contratos.

Por su parte, es atingente a la temática lo expuesto por Hernández y Gatica, quienes comienzan su análisis sosteniendo que la LPC no contiene un estatuto que regule la responsabilidad civil por servicio defectuoso, siendo un tema relevante que ha sido soslayado en el debate parlamentario. A juicio de los autores, sobre la base de ese diagnóstico, la normativa actual dista de proporcionar un soporte adecuado a la responsabilidad civil en razón de que no suministra los pormenores que exige este estatuto en particular. Con ello, se materializa una clara desprotección a los consumidores, quienes son precisamente el objeto de protección de esta ley ${ }^{79}$. Por ende, en observancia de las circunstancias descritas, sumado a las fuertes asimetrías en las que están envueltas las relaciones de consumo, la propuesta de los autores citados aboga por una adecuada protección de los derechos de los consumidores, que en responsabilidad civil se traduce en salvaguardar su derecho a la seguridad y la indemnización ${ }^{80}$.

En concreto, de lo planteado por Hernández y Gatica se destacan las siguientes ideas sobre el artículo 23 inciso $1 .^{\circ}$ LPC:

1) no es una regla sobre la carga de la prueba de negligencia, de forma tal que no es deber del consumidor probarla;

2) en razón del carácter general de la norma, abogan por una aplicación supletoria de las normas del Código Civil, entendidas desde una lógica de protección al consumidor;

3) proponen la aplicación de las presunciones de culpabilidad que invertirían la carga de la prueba en beneficio de la víctima; $y$,

4) indican que

"de comprobarse el incumplimiento del deber de seguridad que recae sobre el proveedor, el consumidor resultaría favorecido con la presunción de negligencia a la que conduce la figura de la culpa infraccional o contra la legalidad" $"$.

Estas ideas propuestas las fundamentan en el gravamen que implica la prueba de la culpa para la víctima, la cual resulta una carga difícil de soportar. En ese sentido, las presunciones de culpa van en auxilio de las víctimas, siendo el autor del daño quien debe probar que ha cumplido con la diligencia debida ${ }^{82}$.

\footnotetext{
${ }^{79}$ Hernández y Gatica (2019), pp. 18- 20.

${ }^{80}$ Hernández y Gatica (2019), p. 32.

${ }^{81}$ Hernández y Gatica (2019), pp. 32-34.

${ }^{82}$ Barros (2020), tomo I, p. 488.
} 
Enlazando lo explicado con los eventos masivos, el consumidor espectador perfectamente podría beneficiarse de más de un tipo de presunción. Así, por ejemplo, podría perseguir la responsabilidad civil del empresario o proveedor a través de la presunción de culpabilidad por el hecho propio del proveedor que ha organizado el evento masivo (artículo 2329 del Código Civil) ${ }^{83}$. Del mismo modo, se podría argumentar una presunción de responsabilidad del empresario o proveedor que brinda el evento por el hecho de uno de sus dependientes (artículo 2320 inciso 4. ${ }^{\circ}$ del Código Civil) ${ }^{84}$. De este modo, si es que se afecta el derecho a la seguridad en el consumo al espectador que asiste a un evento masivo, éste se vería beneficiado con las presunciones de culpa que, como se indicó, se relacionan a su vez a la figura de la culpa infraccional o contra la legalidad.

Sea cualquiera el camino a seguir, las opciones esbozadas optan por la aplicación de la culpa infraccional, concepto que establece que una vez que se genera un accidente consecuencia de la infracción a un deber de cuidado establecido por la ley, el acto deberá ser tenido por culpable sin que sea necesario entrar en otras calificaciones ${ }^{85}$. Ya sea a través de la infracción de las normas de consumo establecidas en la LPC (en específico, para efectos de este trabajo incumben las relativas a la seguridad en el consumo) o a través de la infracción a una de las normas que consagran las presunciones de culpa del Código Civil, lo cierto es que ambas posibilidades dan por sentada la culpabilidad del proveedor. Cabe recalcar que esta es una presunción de culpabilidad y no de responsabilidad, motivo por el cual al proveedor le es posible probar que ha actuado con la diligencia debida. En ese sentido, si bien los efectos aludidos son similares a la responsabilidad objetiva, se diferencian en que en las presunciones de culpa se admite la prueba de la diligencia ${ }^{86}$.

Por último, en lo que refiere a la prueba de la relación causal, cabe destacar que dentro del artículo 50 letra $\mathrm{H}$ inciso $5^{\circ}$ de la LPC, incluido a partir de la reforma introducida por la ley 21081, se instaura la carga dinámica de la prueba en función a la disponibilidad y facilidad probatoria que posea cada una de las partes. En ese sentido, la norma enseñada estipula que

"el tribunal podrá distribuir la carga de la prueba conforme a la disponibilidad y facilidad probatoria que posea cada una de las partes en el litigio, lo que comunicará a ellas para que asuman las consecuencias que les pueda generar la ausencia o insuficiencia de mate-

\footnotetext{
${ }^{83}$ Véase Barros (2020), tomo i, p. 154 y ss.

${ }^{84}$ Véase Barros (2020), tomo I, p. 179 y ss.

${ }^{85}$ Barros (2020), tomo I, p. 104.

${ }^{86}$ Barros (2020), tomo I, pp. 488-489.
} 
rial probatorio que hayan debido aportar o el no rendir la prueba correspondiente de que dispongan en su poder".

El contenido de este artículo, aplicable solamente en los procedimientos de acciones individuales de indemnización de perjuicios por infracción a la LPC, permite al juez, bajo ciertos supuestos, distribuir de forma distinta las cargas probatorias dentro del juicio, lo que puede tener repercusiones en la prueba de la responsabilidad. Esta reciente modificación, no sólo complementa lo explicado en los párrafos precedentes, sino que también potencia la posibilidad de que lo argumentado se materialice.

b) Sobre la responsabilidad infraccional

En segundo término, corresponde referirse a la responsabilidad infraccional del proveedor de eventos masivos. El hecho de que el artículo 23 inciso $1 .^{\circ}$ LPC comience con "cometerá infracciones", sumado a lo estipulado en el artículo $1 .^{\circ} \mathrm{LPC}$, que delimita dentro del objeto de la ley el establecer las infracciones en perjuicio del consumidor, hacen que no hayan dudas respecto al carácter infraccional de la norma ${ }^{87}$, sin perjuicio de que ya se ha argüido sobre la responsabilidad civil que subyace del mismo.

La imposición de la multa, impuesta por el legislador, es un castigo a 212 aquel proveedor que con un comportamiento negligente le ha generado un daño al consumidor ${ }^{88}$. En supuestos de eventos masivos, la falta de observancia en la adopción de medidas de seguridad en la realización de un evento masivo, es razón suficiente para el establecimiento de la responsabilidad infraccional.

$\mathrm{El}$ artículo 23 inciso $2 .^{\circ}$ estipula que serán sancionados con multa de hasta 2250 unidades tributarias mensuales, los organizadores de espectáculos públicos, incluidos los artísticos y deportivos, que pongan en venta una cantidad de localidades que supere la capacidad del respectivo recinto. $\mathrm{Al}$ referirse solamente a casos de sobreventa, el precepto anterior no resulta del todo útil para los casos del incumplimiento del deber de seguridad del proveedor en eventos masivos. Por tanto, se debe citar el artículo 24 LPC, que indica que, a falta de sanción especial en la ley, las infracciones serán sancionadas con multa de hasta 300 unidades tributarias mensuales. Cabe mencionar que se considerará como circunstancia agravante en la determinación de la responsabilidad contravencional, el haber puesto en riesgo la seguridad de los consumidores o de la comunidad, aun no habiéndose causado daño (artículo 24 inciso $5 .^{\circ}$ letra d) LPC).

${ }^{87}$ Barrientos y Contardo (2013), p. 557 y Fernández (2003), pp. 23-24.

${ }^{88}$ Fernández (2003), p. 24. 
En suma, el proveedor en los casos en que ofrece servicios de eventos masivos queda expuesto a que se le apliquen ambos regímenes de responsabilidad del artículo 23 inciso $1 .^{\circ} \mathrm{LPC}^{89}$.

\section{Responsabilidad en casos de relación directa consumidor y proveedor intermediario}

Como se configuró con anterioridad, los eventos masivos son un supuesto de aplicación del artículo 43 LPC. Cabe preguntarse si la subsunción que se genera del proveedor intermediario, en el puesto del proveedor que materialmente efectúo la prestación, acarrea la consecuencia de responder con los mismos alcances que en los casos que el consumidor se relaciona sin intermediario mediante.

$\mathrm{Al}$ respecto, el régimen del proveedor intermediario se considera uno de responsabilidad objetiva ${ }^{90}$ o estricta. En consecuencia, para que el daño revista los atributos necesarios para desencadenar el régimen de responsabilidad del artículo 43 LPC es necesario que proceda del incumplimiento de las obligaciones contractuales, tal como señala la norma.

Adicionalmente, se debe advertir que, normalmente, estos casos debiesen conllevar responsabilidad directa, donde no está la atención puesta en si la conducta del proveedor efectiva fue diligente o no. Por ende, el caso de los proveedores intermediadores es un buen ejemplo donde se distingue la acción civil de la infraccional, no siendo necesaria la procedencia de la segunda para la imposición de la primera ${ }^{91}$. Esto también representa una diferencia entre las implicancias que acarrea la responsabilidad por incum-

${ }^{89}$ Una sentencia que ejemplifica lo expuesto es la dictada por la Corte de Apelaciones de Santiago, que condenó a la empresa organizadora del evento a: "I.- Que la demandada ha infringido además lo dispuesto en el artículo 23 de la Ley 19.496; II.- Que se condena a la demandada al pago de tres multas de 50 UTM cada una, por las infracciones cometidas; III.Que la demandada deberá además indemnizar al grupo de personas que sufrieron pérdida o deterioro de sus enseres personales, cuyo quantum se determinará en la etapa de cumplimiento de esta sentencia. IV.- Que la demandada deberá pagar una indemnización adicional de 0,15 UTM respecto de cada uno de los consumidores que reclamaron ante el SERNAC; v.- Que se ordena hacer las publicaciones dispuestas en extracto realizado por el Secretario del Tribunal, en dos oportunidades distintas en el Diario La Tercera, con un intervalo de entre 3 a 5 días entre ambas publicaciones; vI.- Que la indemnización de $\$ 13.500$ dispuesta en la sentencia de primer grado deberá ser pagada directamente por el demandado a los consumidores sin necesidad de la comparecencia de los interesados en la forma prevista en el artículo $54 \mathrm{C}$ de la Ley N 19.496”. SERNAC con Sach Producciones y Eventos Ltda (2018).

${ }^{90}$ Contardo (2013a), p. 909 y Córdova (2016), p. 51.

${ }^{91}$ En ese sentido, Rodríguez (2010) estima que la responsabilidad del intermediario no puede ser infraccional, p. 701. Del mismo modo, CONTARdo (2013a) estima que la responsabilidad del intermediario es civil y no infraccional, p. 908. 
plimiento con los casos de consumidor con proveedor sin intermediador mediante, donde sí concurre la responsabilidad infraccional.

Con todo, cabe recordar que el mismo artículo 43 LPC consagra el derecho de repetición que ostenta todo proveedor intermediario en contra de la empresa proveedora que realmente ha realizado el evento masivo. Como indica parte de la doctrina, se estaría en presencia de una responsabilidad impuesta por ley, destinada a asegurar la solvencia del deudor para los efectos del pago de la respectiva indemnización ${ }^{92}$. De esta forma, una vez protegido los intereses y derechos del consumidor, nada obsta a que el proveedor intermediario persiga la responsabilidad del proveedor que prestó el servicio efectivamente.

\section{Medios de EXoneración}

Antes de abordar las posibles exenciones de responsabilidad en estos supuestos se debe hacer una distinción, según estemos en presencia de un proveedor efectivo o intermediario, en razón del distinto régimen de responsabilidad que rige cada una de estas hipótesis.

En ese orden de cosas, por un lado, respecto a los casos en que el proveedor efectivamente ha prestado el servicio, se establece un régimen de presunción de culpa, donde ya se ha señalado que es posible exonerarse por parte del proveedor a través de la prueba de la diligencia debida en el caso concreto.

Por otro lado, en el caso del proveedor intermediario, según ya se señaló, se está en presencia de un régimen de responsabilidad estricta. Asumiendo ello, siguiendo a Barros, el principio subyacente es que sólo serán reparados aquellos daños que sean resultante del riesgo definido por la ley ${ }^{93}$. Así, en eventos masivos, la primera cuestión a determinar será si los daños son consecuencia de los riesgos que se han estipulado en la LPC -que justifican el régimen de responsabilidad estricta- y no de otros.

Además de las hipótesis mencionadas y sus respectivas diferencias iniciales, cabe señalar que en ambos regímenes es posible la configuración de dos alternativas como medios de exoneración, a saber: la participación del consumidor en su propio daño y el caso fortuito. A continuación, se analizará cada una de estas causales.

\footnotetext{
${ }^{92}$ Rodríguez (2015), p. 84.

${ }^{93}$ Barros (2020), tomo I, p. 500.
} 


\section{La participación del consumidor en su propio daño}

Lo planteado hasta el momento se ha propuesto teniendo como referencia a un espectador "ideal", un asistente a un evento masivo que tiene un comportamiento correcto, ejemplar durante el desarrollo de la actividad, durante la ejecución del contrato. No obstante, distinto será el caso del espectador que es negligente en su actuar, es decir, no se puede considerar de la misma forma al asistente que se instala en lugares que expresamente están prohibidos o inapropiados, o al que se expone de forma irresponsable a mayores riesgos que el organizador de un evento no tendría por qué soportar.

En cuanto a lo que estipula la LPC, ésta no sólo establece derechos a los consumidores, sino que también deberes. Uno de ellos se encuentra en el artículo $3^{\circ}$ inciso primero letra d), el cual estipula que el consumidor tiene el deber de evitar los riesgos que le puedan afectar. Siguiendo a Isler, se debe considerar que, por una parte, los deberes de los consumidores -entre ellos el de evitar riesgos- son verdaderas prescripciones que son vinculantes para los usuarios y, por otra, que éstos son correlativos con los derechos, de forma tal que si no se cumplen los primeros no será posible exigir el cumplimiento de los segundos ${ }^{94}$. Como indica la autora, el consumidor que se protege es aquel que emplea una diligencia ordinaria, no resultando aplicable la LPC a aquel que tiene un comportamiento basado en la mala fe, con dolo o negligencia inexcusable ${ }^{95}$. Con ello, se procura que el consumidor, en este caso espectador, tenga un comportamiento tal que no lo exponga a un riesgo de forma imprudente. Como puntualiza Corral, este deber no puede significar que se eviten totalmente todos los riesgos, pues ello es imposible en la práctica, sino que debe ser entendido como un deber de autocuidado que incumbe a todas las personas que participan en el tráfico de bienes y servicios ${ }^{96}$.

A las estipulaciones normativas contenidas en la LPC, es menester añadir lo indicado por el Código Civil, el cual, entendido como norma supletoria, reconoce en su artículo 2330 una regla de atenuación de responsabilidad si la víctima se expuso imprudentemente al daño. Siguiendo a San Martín, a pesar de que no existe una norma equivalente en materia

${ }^{94}$ ISLER (2011), pp. 73-74.

${ }^{95}$ ISLER (2011), p. 76.

${ }^{96}$ Corral (2013a), p. 113. En igual sentido, Isler (2019), p. 252. En países como España, esto se analiza en sede extracontractual. En este tipo de supuestos se fundamenta la posible exoneración o atenuación de responsabilidad del organizador del evento, en virtud de que el actuar de la víctima/espectador conlleva una negligencia que explica el resultado dañoso. Véase Medina (2004), p. 257. 
de incumplimiento de obligaciones de carácter contractual ${ }^{97}$, existen buenas razones para aplicar la regla de "la culpa concurrente de la víctima" -reducción de indemnización por exposición imprudente al daño-a materias contractuales, más aun en materias de consumo, el cual al ser un estatuto protector, tiende a ser más benévolo con el consumidor que el proveedor ${ }^{98}$. En consecuencia, es aplicable la regla en sede contractual ${ }^{99}$. Del mismo modo, Corral comparte la aplicación del artículo 2330 en materias de consumo, especialmente en aquellos casos en que existe un incumplimiento del deber de cuidado del proveedor y al mismo tiempo una falta de autocuidado del consumidor ${ }^{100}$. Por tanto, independiente de cual sea la sede en la cual se desarrolle la problemática, la figura tiene cabida tanto en materias contractuales como extracontractuales.

En virtud del principio de buena $\mathrm{fe}^{101}$, presente tanto en el derecho de los contratos como en el derecho de consumo, los deberes de diligencia recaen no solamente sobre el productor o proveedor del evento masivo, sino que también sobre los espectadores o consumidores que asisten al mismo. No resulta lógico que la empresa organizadora deba responder incluso en los casos en que el espectador se exponga a situaciones evitables, riesgos previsibles en la realización de un acto de este tipo. En materias contractuales, como advierte Pizarro, se está ante un problema causal debido a que es

"la conducta del acreedor lo que explica en forma causal su propio daño, cuya indemnización no puede reclamar atendido que el origen del mismo está en su propio actuar” ${ }^{102}$.

En suma, es la propia conducta del espectador, que incumple su deber de buen comportamiento durante el evento masivo, la que limita las posibilidades que proporciona el derecho contractual ${ }^{103}$.

${ }^{97}$ SAn Martín (2018), p. 183.

${ }^{98}$ SAn Martín (2018), p. 193.

${ }^{99}$ San Martín concluye señalando que es posible aplicar la regla contenida en el artículo 2330 del Código Civila casos de responsabilidad contractual atendiendo que: "i) el hecho de que la regla se originó en sede contractual; ii) el hecho de que en ordenamientos jurídicos extranjeros las misma regla se encuentra establecida a propósito de ambos estatutos; iii) el hecho de que resulta contrario al principio general de buena fe admitir que la sola existencia de un contrato autoriza para actuar de manera negligente”. SAN MARTín (2018), p. 207.

${ }^{100}$ Corral (2013a), p. 114. Así también, Isler (2019), p. 252.

${ }^{101}$ Artículo 1546 del Código Civil señala que "Los contratos deben ejecutarse de buena fe, y por consiguiente obligan no sólo a lo que en ellos se expresa, sino a todas las cosas que emanan precisamente de la naturaleza de la obligación, o que por la ley o la costumbre pertenecen a ella".

${ }^{102}$ Pizarro (2014), p. 624.

${ }^{103}$ Pizarro (2014), p. 628. 
Así las cosas, se debe ponderar la actuación del asistente o consumidor en concreto, la diligencia o negligencia que éste tuvo en su actuar, y sopesar dicha actitud con la posible responsabilidad que tenga el proveedor $\mathrm{u}$ organizador del evento por no prever los potenciales daños que se podían generar producto de no haber adoptado todas las medidas de seguridad pertinentes.

Lo mismo ocurre en el caso del proveedor intermediario. Aunque en el régimen de responsabilidad estricta no está puesta la atención en la culpa del demandado, ello no es obstáculo para poder centrarse en sí, en el caso concreto, el consumidor o asistente ha tenido un comportamiento imprudente. Barros distingue que el imponer un régimen reforzado de responsabilidad no debe llevar al extremo de considerar que la víctima carece de cargas de cuidado que tendría bajo un régimen de responsabilidad por culpa ${ }^{104}$.

\section{Caso fortuito}

La LPC no proporciona ningún tratamiento, ni provee información de este medio de exoneración que tiene el acreedor o proveedor para liberarse o dar por cumplido el deber de seguridad que debe satisfacer durante la ejecución del contrato. A falta de norma expresa, será tarea del juez valorar las circunstancias del caso concreto y analizar la procedencia o no del caso fortuito.

Con ese escenario, es ineludible acudir a las reglas del Código Civil como régimen supletorio en estas materias, el cual opera como norma integradora de las normas de la ley de consumo. A través de las normas de este cuerpo legal, es posible desarrollar el estudio y tratamiento del caso fortuito en estas materias, y al menos dar un esbozo para tener ciertas nociones de cara al desafío que deben afrontar los jueces en estas circunstancias.

Atendido el escenario descrito, el artículo 45 del Código Civil señala que el caso fortuito es "el imprevisto a que no es posible resistir". Siguiendo a Corral, esta institución opera como defensa dado que produce un quiebre del nexo causal, de forma tal que los daños ya no serán imputables al demandado sino al hecho que constituye el caso fortuito ${ }^{105}$. El mismo autor indica que se incluirán dentro de este concepto no sólo los hechos naturales (como terremotos, incendios, entre otros) sino también actuaciones humanas ${ }^{106}$ (coloca de ejemplo a una persona a la cual empujan de modo irresistible y rompe una vitrina de tienda, la que estaría exenta de responsabilidad dado que ha sido materialmente utilizada -sin su voluntad- para

\footnotetext{
${ }^{104}$ Barros (2020), tomo i, p. 500.

${ }^{105}$ Corral (2010), p. 463.

${ }^{106}$ Corral (2013b), p. 107.
} 
generar un daño). En los eventos masivos las actuaciones humanas deben ser observadas con cautela, porque precisamente parte de las medidas de seguridad que deben proporcionar los proveedores pasan por asegurar que los otros asistentes no van a generar riesgos (así, por ejemplo, bengalas o bombas de ruido en un estadio difícilmente podrán ser consideradas caso fortuito). La masividad comporta riesgos que deben ser previstos por aquellos proveedores que brindan espectáculos de alta convocatoria. En este aspecto, la previsibilidad jugará en ese sentido un papel principal, toda vez que permite distinguir la acción culpable del caso fortuito, siendo este último integrado por todas aquellas circunstancias que no pudieron ser objeto de deliberación al momento de actuar ${ }^{107}$. Será tarea del proveedor probar ello.

En cuanto al régimen de los proveedores intermediarios, éstos no podrán alegar caso fortuito por negligente intervención del proveedor efectivo. Cabe recordar que estamos en presencia de una responsabilidad directa del proveedor intermediario, y adicionalmente, como indica Contardo, una responsabilidad por el hecho propio, pues "ha asumido como propia la prestación que se ha descargado en el tercero conocido por el consumidor" ${ }^{108}$. En el caso del proveedor intermediario, sería complicado establecer una regla general referida al caso fortuito como excusa en materia de responsabilidad estricta, dado que el interés del legislador es que quien desarrolla la actividad se haga cargo del riesgo asociado a la actividad. Lo normal es que en que en estos regímenes esté prevista alguna norma especial que estipule e indique al caso fortuito como una excusa ante el incumplimiento ${ }^{109}$.

Por último, en la hipótesis de que se acepte el caso fortuito como causal de exoneración en materias de consumo, al proveedor le correspondería probar lo que exige el artículo 45 del Código Civil. Tradicionalmente se ha entendido que sus requisitos son tres: la exterioridad, la imprevisibilidad y la irresistibilidad del hecho constitutivo del mismo ${ }^{110}$. Dichos requisitos deben relacionarse con el artículo 1547 inciso $2 .^{\circ}$ del Código Civil que señala que el deudor no es responsable del caso fortuito (a menos de que se haya constituido en mora o que haya sobrevenido por su culpa). En consecuencia, relacionando lo expuesto a la hipótesis de los eventos masivos, el proveedor tendrá que demostrar la intervención de un caso fortuito como una ruptura del vínculo causal entre el incumplimiento del deber de seguridad y el daño que ha sufrido el espectador.

\footnotetext{
${ }^{107}$ Barros (2020), tomo I, p. 95.

${ }^{108}$ Contardo (2013a), p. 912.

${ }^{109}$ Barros (2020), tomo I, p. 502.

${ }^{110}$ Pizarro (2010), p. 173.
} 


\section{Conclusiones}

En función de lo expuesto y argumentado en la presente investigación, es posible arribar a las siguientes conclusiones:

1) Se remarca la necesidad de prestar mayor atención al fenómeno de masividad en Chile, tanto por sus especiales características como por ser una fuente importante de potenciales daños.

2) A pesar de no tener un tratamiento específico por ley, se defiende la aplicación de la LPC como marco legal aplicable a los eventos masivos. Este conjunto normativo permite que, al estar resguardada la relación de consumo entre proveedor (organizador de evento) y consumidor (asistente a evento), este último tenga derecho a la seguridad en el consumo y, en consecuencia, a ser indemnizado en el caso de ocurrencia de daños en el evento masivo.

3) En relación a las partes contratantes, cabe concluir que, de la relación tripartita entre asistente, ticketera y productora de eventos, puede surgir más de un tipo de relación jurídica. Así, además del vínculo existente entre el consumidor (ya sea jurídico o material) con el prestador efectivo sin intermediario mediante, se debe destacar que las ticketeras, en los casos que intervienen, les es aplicable el artículo 43 LPC, considerándose proveedores intermediarios. En consecuencia, el consumidor podrá demandar directamente a la empresa que media la compraventa de entradas, sin perjuicio de los derechos de repetición que tiene el proveedor intermediario en contra del prestador efectivo del servicio.

4) Atendida las circunstancias que subyacen a un evento masivo, se concluye que aproximarse exclusivamente desde una perspectiva contractual es insuficiente. La presente investigación defiende la aplicación de la tutela aquiliana, sin perjuicio de reconocer que el asistente dispone de un concurso de acciones, siendo éste quien valorará de mejor forma el cómo proteger sus derechos.

5) Respecto a los alcances del incumplimiento del deber de seguridad. Por una parte, la seguridad es relevante toda vez que los asistentes que acuden a un evento masivo, lo hacen con la legítima confianza de que el organizador ha adoptado las medidas de protección adecuadas. Por otra parte, se constata la escasa jurisprudencia específica y la ausencia de aportes de la doctrina nacional en lo relativo a espectáculos masivos. Así también, teniendo presente que, en eventos masivos, el no exponer a riesgos innecesarios a los consumidores por parte de los proveedores conlleva múltiples obligaciones que no se encuentran en otro tipo de servicios, la investigación proporciona las particularidades del deber de seguridad a través 
de lo establecido sobre el mismo en otras situaciones de hecho y valorando lo indicado por doctrina extranjera que sí ha estudiado el tema de los eventos masivos. Igualmente, se subraya el derecho de todo consumidor a la reparación e indemnización oportuna y adecuada de todos los daños sufridos por el incumplimiento, siendo derechos conexos y complementarios con el derecho a la seguridad en el consumo.

6) Las responsabilidades en las que puede incurrir el proveedor de un evento masivo podrán ser tanto civiles como infraccionales, debiendo distinguir si se está ante un proveedor intermediario o efectivo.

7) En el caso del proveedor efectivo, se concluye que por el incumplimiento del deber de seguridad procede tanto la responsabilidad infraccional como la civil. En específico, se prevé un régimen de responsabilidad civil fundado en el artículo 23 inciso $1 .^{\circ} \mathrm{LPC}$, en el cual se beneficia a la víctima a través de herramientas como la culpa infraccional y la aplicación de presunciones de culpa. Se explicó que ello se puede sustentar tanto por lo establecido en la ley n. ${ }^{\circ} 18287$ (artículo 14), como por una aplicación en beneficio de los consumidores de las normas contenidas en el Código Civil, a partir de las presunciones de culpa e instituciones como la culpa infraccional, el cual opera como norma supletoria en materias de consumo.

8) En el caso del proveedor intermediario, se resalta tanto el carácter objetivo de la responsabilidad civil como la improcedencia de aquella infraccional.

9) El asumir un régimen de responsabilidad por ilícito infraccional o por culpa presunta, o incluso de responsabilidad objetiva en el caso de los proveedores intermediarios, no es óbice para que el proveedor pueda defenderse. En ese sentido, tanto la participación del consumidor en su propio daño como el caso fortuito, pueden ser considerados como medios de exoneración del cumplimiento de la obligación de seguridad que surge de la realización de eventos masivos.

\section{BibLIOGRAFÍA CITADA}

Abeliuk Manasevich, René (2008). Las obligaciones. $5^{\text {a }}$ edición. Santiago: Editorial Jurídica de Chile, tomo I.

BARAONA GonZÁLEZ, Jorge (2014). "La regulación contenida en la ley 19.496 sobre protección de los derechos de los consumidores y las reglas del código civil y 
comercial sobre contratos: un marco comparativo". Revista Chilena de Derecho, vol. 41, n. ${ }^{\circ}$, Santiago.

Barrientos Zamorano, Marcelo (2010). "Jurisprudencia por daños en estacionamiento de vehículos regido por la "Ley del consumidor". Revista de Derecho de la Pontificia Universidad Católica de Valparaíso, n. ${ }^{\circ}$ 34, Valparaíso.

BARrientos CAmus, Francisca (2011). "Algunas reflexiones sobre el desbordamiento de la responsabilidad infraccional en la ley $\mathrm{N}^{\circ}$ 19496". Revista de Derecho de la Empresa, n. ${ }^{\circ}$ 24, Santiago.

Barrientos Camus, Francisca (2012). "Función del artículo 23 como fuente ambigua de responsabilidad en la ley de protección al consumidor. Alguna jurisprudencia reciente", en Francisca Barrientos Camus, Iñigo de la MaZA Gazmuri y Carlos Pizarro Wilson. Consumidores. Santiago: Legal Publishing.

Barrientos Camus, Francisca y Juan Ignacio Contardo GonzÁlez (2013). "Artículo 23 inciso $1^{\circ}$. Diversas infracciones a la ley", en Iñigo DE LA MAZA GAZMuri y Carlos Pizarro Wilson (dirs.). La protección de los derechos de los consumidores: Comentarios a la ley de protección a los derechos de los consumidores. Santiago: Legal Publishing.

Barrientos Camus, Francisca (2014). "La articulación de remedios en el sistema de la responsabilidad civil del consumo". Revista de Derecho de la Pontificia Universidad Católica de Valparaíso, n. ${ }^{\circ}$ 42, Valparaíso.

Barrientos Camus, Francisca (2015). "La evolución judicial del concepto de consumidor. La importancia de la destinación final y la clasificación de los consumidores materiales y jurídicos", en Álvaro Vidal Olivares, Gonzalo Severin Fuster y Claudia Mejías Alonzo (editores). Estudios de Derecho Civil $X$. Santiago: Thomson Reuters.

Barrientos Camus, Francisca (2019). Lecciones de derecho del consumidor. Santiago: Legal Publishing.

Brantt Zumarán, María Graciela y Claudia Mejías Alonzo (2018). "El contrato de servicios como categoría general en el derecho chileno. Su contenido y rasgos distintivos". Revista Ius Et Praxis, vol. 24, n. ${ }^{\circ}$ 3, Talca.

Barros Bourie, Enrique (2020). Tratado de responsabilidad extracontractual. Santiago: Editorial Jurídica de Chile, tomo I.

Boetsch Gillet, Cristián (2011). La buena fe contractual. Santiago: Editorial Jurídica de Chile.

CASAdo Andrés, Blanca (2015). Responsabilidad civil deportiva daños a espectadores y terceros. Madrid: La Ley.

Casado Andrés, Blanca (2018). “Espectadores y fútbol”. Diario La Ley (Estudios doctrinales), n. ${ }^{\circ}$ 9130, Madrid.

Coвасho Gómez, José Antonio (2015). "Daños en espectáculo. En especial los espectáculos deportivos", en Antonio OrTí y María del Carmen García (directores). La Responsabilidad Civil por daños Causados por servicios defectuosos. Pamplona: Thomson Reuters Aranzadi. 
Contardo González, Juan Ignacio (2013a). "Artículo 43. Responsabilidad del proveedor intermediario", en Iñigo DE la MAZA Gazmuri y Carlos Pizarro Wilson (directores). La protección de los derechos de los consumidores: Comentarios a la ley de protección a los derechos de los consumidores. Santiago: Legal Publishing.

Contardo GonzÁlez, Juan Ignacio (2013b). “Artículo 41. Garantía legal para los servicios”, en Iñigo De la Maza Gazmuri y Carlos Pizarro Wilson (directores). La protección de los derechos de los consumidores: Comentarios a la ley de protección a los derechos de los consumidores. Santiago: Legal Publishing.

Contardo González, Juan Ignacio (2013c). "Artículo $3^{\circ}$ e). Derecho a la reparación e indemnización”, en Iñigo de la Maza Gazmuri y Carlos Pizarro Wilson (directores). La protección de los derechos de los consumidores: Comentarios a la ley de protección a los derechos de los consumidores. Santiago: Legal Publishing.

Córdova Yukich, Diego (2016). "Régimen de responsabilidad de compañías de descuento por internet. ¿proveedores intermediarios?”. Revista de Derecho Universidad Católica del Norte, año 23, n. ${ }^{\circ}$ 2, Coquimbo.

Corral Talciani, Hernán (1999). "Ley de protección al Consumidor y responsabilidad civil”, en Hernán Corral TAlCiani (ed.). Derecho del consumo y protección al consumidor. Estudios sobre la Ley $N^{0} 19.496$ y las principales tendencias extranjeras. Santiago: Ediciones Universidad de los Andes.

Corral Talciani, Hernán (2010). "Responsabilidad civil en la construcción de viviendas reflexiones sobre los regímenes legales aplicables a los daños provocados por el terremoto del 27 de febrero de 2010". Revista Chilena de Derecho, vol. 37, n. ${ }^{\circ}$, Santiago.

Corral Talciani, Hernán (2013a). "Artículo $3^{\circ}$ d). Derecho a la seguridad en el consumo servicios de bienes y servicios", en Iñigo dE LA MAZA GAZMuri y Carlos Pizarro Wilson (directores). La protección de los derechos de los consumidores: Comentarios a la ley de protección a los derechos de los consumidores. Santiago: Legal Publishing.

Corral Talciani, Hernán (2013b). Lecciones de responsabilidad civil extracontractual. Santiago: Thomson Reuters.

Echevesti, Rosario y Zudaire, Lucas (2018). "Responsabilidad por daños en espectáculos públicos: Avance y retroceso. 'Mosca' y 'Arregui'”. Revista Derechos En Acción (REDEA), n. ${ }^{\circ}$ 9, Buenos Aires.

Eyzaguirre BaEza, Cristóbal y Javier Rodríguez Diez (2013). "Expansión y límites de la buena fe objetiva - a propósito del "proyecto de principios latinoamericanos de derecho de los contratos". Revista Chilena de Derecho Privado, n. ${ }^{\circ}$ 21, Santiago.

FACCO, Javier Humberto (2009). "El principio de buena fe objetiva en el derecho contractual argentino". Revista de Derecho Privado, Universidad Externado de Colombia, n. ${ }^{\circ} 16$, Bogotá.

Fernández Fredes, Francisco (2003). Manual de derecho chileno de protección al consumidor. Santiago: LexisNexis Chile. 
FuenZalida Robledo, Eduardo (2018). "El acto de consumo como hecho y la responsabilidad civil”. Revista de Derecho Universidad Católica del Norte, año 25, n. ${ }^{\circ} 1$, Coquimbo.

GuERRERo BECAR, José Luis (2008). "La distinción entre contravención infraccional e incumplimiento contractual”, en Alejandro GuZMÁn BRITO (ed.). Colección de estudios de Derecho Civil en homenaje a la profesora Inés Pardo de Carvallo. Valparaíso: Ediciones Universitarias de Valparaíso.

Hernández Paulsen, Gabriel y María Paz Gatica Rodríguez (2019). "Protección del consumidor y responsabilidad civil por producto o servicio defectuoso". Revista de estudios de la justicia, n. ${ }^{\circ}$ 31, Santiago.

IsLER Soto, Erika (2011). "La relatividad de los derechos subjetivos de los consumidores". Revista de Derecho (Valdivia), vol. 24, n. ${ }^{\circ}$ 2, Valdivia.

IsLER SOTO, Erika (2015). "Las normas que dan origen a la responsabilidad civil y a la responsabilidad infraccional en la Ley 19.496". Revista Chilena de Derecho y Ciencia Política, vol. 6, n. ${ }^{\circ}$ 2, Temuco.

IsLer Soto, Erika (2019). Derecho del consumo: nociones fundamentales. Valencia: Tirant lo Blanch.

Lorenzini Barría, Jaime y Joaquín Polit Corvalán (2013). "El régimen de la nulidad y la resolución en el derecho del consumidor chileno", en CARMEN Domínguez et al. (coord.). Estudio de Derecho Civil,Jornadas Nacionales de Derecho Civil, Santa Cruz 2012. Santiago: Legal Publishing.

Maldonado Calderón, Sonia (1998). "Particularidad de los contratos de adhesión en la ley 19.496”. Revista de Derecho de la Pontificia Universidad Católica de Valparaíso, n. ${ }^{\circ}$ 19, Valparaíso.

Medina Alcoz, María (2004). La asunción del riesgo por parte de la víctima. Riesgos taurinos y deportivos. Madrid: Dykinson.

Momberg Uribe, Rodrigo (2013). "Artículo $1^{\circ} \mathrm{N}^{\circ} 1$. Definición consumidores y usuarios", en Iñigo DE LA MAZA GAZMURI y Carlos PizarRo WiLson (directores). La protección de los derechos de los consumidores: Comentarios a la ley de protección a los derechos de los consumidores. Santiago: Legal Publishing.

Palazón Garrido, María Luisa (2002). "Reflexiones sobre la responsabilidad civil por los actos violentos cometidos por las masas de espectadores en los espectáculos deportivos". Revista jurídica de deporte y entretenimiento deportes, juegos de azar, entretenimiento y música, n. ${ }^{\circ}$ 8, Cizur Menor.

Piñeiro Salguero, José (2005). "Accidentes deportivos: lesiones consentidas. Análisis de la doctrina de la asunción del riesgo en la responsabilidad civil en el deporte". Indret: Revista para el Análisis del Derecho, n. ${ }^{\circ}$ 3, Barcelona.

Pizarro Wilson, Carlos (2010). "Daños en la construcción, fuerza mayor y terremotos". Revista de Derecho de la Pontificia Universidad Católica de Valparaíso, n. ${ }^{\circ} 34$, Valparaíso.

Pizarro Wilson, Carlos (2014). "El hecho del acreedor en la responsabilidad contractual”, en Álvaro Vidal Olivares, Gonzalo Severin Fuster y Claudia Mejías Alonzo (editores). Estudios de Derecho Civil X. Santiago: Thomson Reuters. 
Quesada Sánchez, José (2009). "Daños sufridos por espectadores de acontecimientos deportivos: repaso de sentencias de interés". Revista de responsabilidad civil, circulación y seguro, n. ${ }^{\circ} 9$, Madrid.

Rodríguez Pinto, María Sara (2010). "La responsabilidad del intermediario de servicios al consumidor (un estudio tentativo del sistema de atribución de responsabilidad del artículo 43 de la Ley sobre Protección de los Derechos de los Consumidores)", en AA.VV. Estudios de Derecho Civil VI,Jornadas Nacionales de Derecho Civil, Olmué 2010. Santiago: Abeledo Perrot - Legal Publishing.

Rodríguez Pinto, María Sara (2014). "Responsabilidad por incumplimiento de contratos de servicios. La protección del consumidor y del cliente por prestaciones defectuosas". Revista Chilena de Derecho, vol. 41, n. ${ }^{\circ} 3$, Santiago.

Rodríguez Grez, Pablo (2015). Derecho del Consumidor. Estudio crítico. Santiago: Legal Publishing Chile.

SAn Martin Neira, Lilian (2018). La culpa de la víctima en la responsabilidad civil. Santiago: DER Ediciones.

Seligrat González, Víctor Manuel (2016). Responsabilidad civil en el deporte. Especial referencia a los eventos deportivos profesionales de masas. Madrid: Editorial Jurídica Sepín.

Ulloa Valenzuela, Pablo (2014). El deber de seguridad de la ley $N^{\circ} 19.496$ en la jurisprudencia. Disponible en: https://derechoyconsumo.udp.cl/wp-content/ uploads/2016/10/El-deber-de-seguridad-de-la-LPDC-en-la-jurisprudenciaPablo-Ulloa.pdf [Fecha de consulta: 28 de abril de 2021].

YzQuierdo Tolsada, Mariano (2008). "El deporte y los espectáculos deportivos en el contexto general de la responsabilidad civil”, en Francisco Javier GómEz Gálligo (coord.). Homenaje al profesor Manuel Cuadrado Iglesias. Pamplona: Aranzadi, vol. 2.

\section{Otros documentos citados}

Consejo Nacional de la Cultura y las Artes (2011). Segunda Encuesta Nacional de Participación y Consumo Cultural. Santiago: Ediciones Cultura.

Consejo Nacional de la Cultura y las Artes (2016). Política Nacional del Campo de la Música 2017-2022. Disponible en: https://www.cultura.gob.cl/wp-content/ uploads/2016/11/politica_musica.pdf [Fecha de consulta: 08 de marzo de 2021].

Consejo Nacional de la Cultura y las Artes (2017). Encuesta Nacional de Participación 2017. Disponible en: https://www.cultura.gob.cl/wp-content/ uploads/2018/03/enpc_2017.pdf [Fecha de consulta: 08 de marzo de 2021].

Intendencia de la región metropolitana, circular n. 28 , de 16 de octubre de 2015, que establece procedimiento para la realización de eventos masivos. Disponible en https://www.bcn.cl/leychile/navegar?i=1083082 [Fecha de consulta: 08 de marzo de 2021].

Intendencia de la vi región del Libertador General Bernardo O’Higgins, resolución exenta n. ${ }^{\circ} 979$, de 05 de marzo de 2020, que aprueba reglamento para autori- 
zación de espectáculos masivos. Disponible en https://www.bcn.cl/leychile/ navegar?i=1143483 [Fecha de consulta: 08 de marzo de 2021].

Servicio Nacional del Consumidor, resolución exenta n. ${ }^{\circ}$ 0186, de 21 de marzo de 2019. Disponible en https://www.sernac.cl/portal/618/articles-9191_archivo_01.pdf [Fecha de consulta: 08 de marzo de 2021].

\section{Normas citadas}

Código Civil, Chile.

Código de Comercio, Chile.

Ley n. ${ }^{\circ} 21081$, modifica ley n. ${ }^{\circ} 19.496$, sobre protección de los derechos de los consumidores. Diario Oficial de la República de Chile, Santiago, 13 de septiembre de 2018.

Ley n. ${ }^{\circ} 20844$, establece derechos y deberes de asistentes y organizadores de espectáculos de fútbol profesional. Diario Oficial de la República de Chile, Santiago, 15 de junio de 2015.

Ley n. ${ }^{\circ}$ 19327, sobre "Derechos y deberes en los espectáculos de fútbol profesional". Diario Oficial de la República de Chile, Santiago, 10 de junio de 2015.

Ley n. ${ }^{\circ} 19955$, modifica la ley n. ${ }^{\circ} 19.946$ sobre protección de los derechos de los consumidores. Diario Oficial de la República de Chile, Santiago, 14 de julio de 2004.

Ley n. ${ }^{\circ}$ 19496, sobre "Normas sobre protección de los derechos de los consumidores". Diario Oficial de la República de Chile, Santiago, 7 de marzo de 1997.

Ley n. ${ }^{\circ} 18287$, "Establece procedimiento ante los juzgados de policía local”. Diario Oficial de la República de Chile, Santiago, 7 de febrero de 1984.

Ley 19/2007, de 11 de julio, “contra la Violencia, el Racismo, la Xenofobia y la Intolerancia en el Deporte”. BOE núm. 166, de 12 de julio de 2007.

Reglamento general de policía de espectáculos públicos y actividades recreativas, el cual fue aprobado por el Real Decreto 2816/1982. BOE núm. 267, de 6 de noviembre de 1982.

Decreto del Ministerio de Salud n. ${ }^{0} 10$ del año 2010, aprueba reglamento de condiciones sanitarias, ambientales y de seguridad básicas en locales de uso público. Diario Oficial de la República de Chile, Santiago, 25 de septiembre de 2010.

\section{Jurisprudencia citada}

Punto Ticket S.A con G.M.E. (2019): Corte de Apelaciones de Santiago, 08 de noviembre de 2019, rol policia local n. ${ }^{\circ} 2054-2018$.

Requerimiento de inaplicabilidad por inconstitucionalidad presentado por Universal Agencia de Turismo Limitada, respecto del artículo 43 de Ley 19.496, sobre protección de los derechos de los consumidores, en causa rol n. ${ }^{\circ} 4898-2007$, de la Corte de Apelaciones de Santiago (2008): Tribunal Constitucional, 18 de mayo de 2008. rol n. ${ }^{\circ} 980-2007$. 
SERNAC con Punto Ticket S.A. (2019): $21^{\circ}$ Juzgado Civil de Santiago, 17 de diciembre de 2019, rol n. ${ }^{\circ}$ 10887-2017.

SERNAC con Sach Producciones y Eventos Ltda (2018): Corte de Apelaciones de Santiago, 02 de marzo de 2018, rol n. ${ }^{\circ}$ 12132-2017.

SERNAC con Sach Producciones y Eventos Ltda (2017): $16^{\circ}$ Juzgado Civil de Santiago, 30 de junio de 2017, rol n. ${ }^{\circ}$ 13639-2015.

SERNAC con T4F Chile S.A. (2016): Corte Suprema, 19 de mayo de 2016, rol n. ${ }^{\circ} 7002-2015$.

SERNAC con Latin Gaming Osorno S.A (2014): 1. ${ }^{\circ}$ Juzgado de Letras de Osorno, 31 de diciembre de 2014, rol n. ${ }^{\circ} 192-2012$.

SERNAC con Ticket Fácil (2013): $7^{\circ}$ Juzgado Civil de Santiago, 29 de noviembre de 2013, rol n. ${ }^{\circ}$ 21700-2011.

SERNAC con Producciones y Eventos Empiredigital (2012): 6. o Juzgado Civil de Santiago, 18 de diciembre de 2012, rol n. ${ }^{\circ}$ 22924-2011.

V. G. C. con Club Deportivo Provincial Osorno S.A.D.P. (2012): Corte Suprema, 10 de septiembre de 2012, rol n. ${ }^{\circ} 1630-2010$.

SiglaS Y ABREVIATURAS

AA.VV. Varios autores

Adj. Adjetivo

Coord. Coordinador

Coords. Coordinadores

Dir. Director

Dirs. Directores

Ed. Editor

Eds. Editores

Et al. Y otros

Etc Etcétera

FPI Formación de Personal investigador

Html HyperText Markup Language

Http Hypertext Transfer Protocol

Inc. Inciso

LPC Ley n. ${ }^{\circ} 19.496$ sobre "Normas sobre protección de los derechos de los consumidores"

Ltda. Limitada

$\mathrm{N}^{\circ} \quad$ Número

p. Página

pp. Páginas

S.A. Sociedad Anónima 
SERNAC Servicio Nacional del Consumidor

ss. Siguientes

UEFA Union of European Football Associations

UTM Unidad Tributaria Mensual

v. gr. verbigracia

Vol. Volumen

www. World Wide Web 